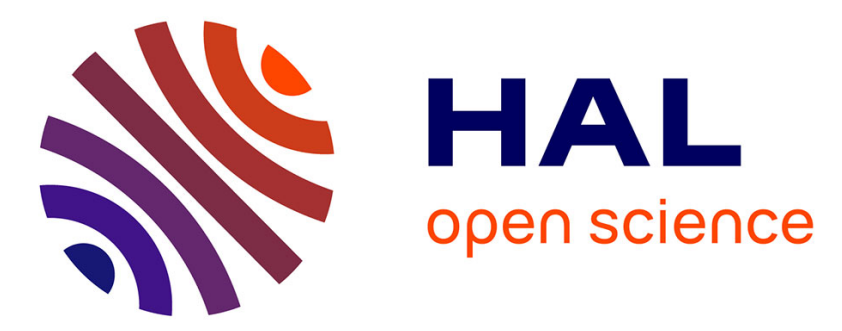

\title{
ATP Induced Modulation in $\pi-\pi$ Stacking Interactions in Pyrene Based Zinc Complexes: Chemosensor Study and Quantitative Investigation of Apyrase Activity
}

Amanpreet Singh, Pushap Raj, Jan Dubowski, Narinder Singh

\section{- To cite this version:}

Amanpreet Singh, Pushap Raj, Jan Dubowski, Narinder Singh. ATP Induced Modulation in $\pi-\pi$ Stacking Interactions in Pyrene Based Zinc Complexes: Chemosensor Study and Quantitative Investigation of Apyrase Activity. Crystal Growth \& Design, 2018, 18 (8), pp.4320-4333. 10.1021/acs.cgd.8b00165. hal-01905587

\section{HAL Id: hal-01905587 \\ https://hal.science/hal-01905587}

Submitted on 8 Nov 2018

HAL is a multi-disciplinary open access archive for the deposit and dissemination of scientific research documents, whether they are published or not. The documents may come from teaching and research institutions in France or abroad, or from public or private research centers.
L'archive ouverte pluridisciplinaire HAL, est destinée au dépôt et à la diffusion de documents scientifiques de niveau recherche, publiés ou non, émanant des établissements d'enseignement et de recherche français ou étrangers, des laboratoires publics ou privés. 


\title{
ATP Induced Modulation in $\pi-\pi$ Stacking Interactions in Pyrene Based Zinc Complex: Chemosensor Study and Quantitative Investigation of Apyrase Activity
}

\author{
Amanpreet Singh ${ }^{a}$, Pushap Raj ${ }^{a}$, Jan J. Dubowski ${ }^{b}$, Narinder Singh ${ }^{a, *}$ \\ ${ }^{a}$ Department of Chemistry, Indian Institute Technology Ropar, Punjab, 140001, India \\ ${ }^{b}$ Laboratory for Quantum Semiconductors and Photon-Based BioNanotechnology, Interdisciplinary \\ Institute for Technological Innovation (3IT), CNRS UMI-3463, Department of Electrical and Computer \\ Engineering, Université de Sherbrooke, 2500 boul. de l’Université, Sherbrooke, Québec J1K \\ 2R1, Canada \\ *Corresponding author (Narinder Singh) E-mail: nsingh@iitrpr.ac.in; Tel: +91-1881242176
}

\begin{abstract}
Fluorescent zinc complexes of 1,2-disubstituted benzimidazole (R1-R3) have been synthesized and characterized using single crystal XRD. The ligands L1-3 were found to be less emissive due to photoinduced electron transfer (PET) mechanism originated from the electron pair of benzimidazole nitrogen. The complexation of ligands with $\mathrm{Zn}(\mathrm{II})$ not only enhances the fluorescent intensity, however also orient the ligands to an new packing. It was observed that the aromatic unit plays a decisive role in the packing of the molecules. The complex R1 has extended the coordination through $\mathrm{C}-\mathrm{H}^{\cdots} \pi$ interaction, whereas complex $\mathbf{R 2}$ involved $\mathrm{C}-\mathrm{H}^{\cdots} \pi$ interaction and $\mathrm{C}-\mathrm{H}{ }^{\cdots} \mathrm{Br}$ interaction for packing in supramolecular architecture. Among these complexes, R3 showed most interesting noncovalent interaction pattern involving $\mathrm{C}-\mathrm{H}^{\cdots} \pi$ interaction, $\mathrm{C}-\mathrm{H}^{\cdots} \mathrm{Br}$ interaction and $\pi-\pi$ stacking between pyrene rings. These noncovalent interactions govern photophysical properties that are sensitive toward microenvironment. Thus, by altering these interactions, the selective sensing for a particular analyte can be achieved. The complexes $\mathbf{R} \mathbf{1}$ and $\mathbf{R} 2$ have shown enhanced emission intensity upon interacting with ATP competitively in the presence of some other tested anions. A ratiometric change in emission spectra of the complex R3 was observed upon binding with ATP in semi-aqueous medium offering the lowest detection limit of $15 \mathrm{nM}$. Upon interaction with ATP the $\pi-\pi$ stacking between pyrene rings breaks and results in a decrease in excimer emission at $470 \mathrm{~nm}$ and increases in monomeric emission intensity at $410 \mathrm{~nm}$. The AFM images of receptor $\mathbf{R} 3$ show that upon addition of ATP to the R3 solution, solvent mediated aggregation takes place, which results in the ratiometric detection. In the DMF solvent system aggregates were formed, whereas in Water:THF solvent system clear solution was
\end{abstract}


converted to a highly viscous gel. To investigate the applications of the prepared sensor, fluorescence response of Hela cells enriched with ATP was observed using fluorescence microscopy. The fluorescence modulation of sensor in living cells makes the receptor practically applicable in a biological environment. Quantitative analysis of apyrase activity has shown that the presented sensor $\mathbf{R 3}$ is capable to monitor the hydrolysis process in the biological system.

Key words: Fluorescent sensor, benzimidazole, pyrene, $\pi-\pi$ stacking, ratiometric, adenosine triphosphate 


\section{INTRODUCTION}

Detection of anionic species in aqueous medium becomes an imperative goal for supramolecular chemistry because these are pervasive in biological system and an play important role in environmental monitoring and diagnosis. ${ }^{1-5}$ Unlike cations; anionic species have different shape and size, hence anionic biomolecules require complementary receptors to encapsulate. ${ }^{6-9}$ The biologically important anionic species such as phosphates, and nucleic bases; due to their diverse size and shape demand the receptor design which is sometimes tedious to develop using synthetic skills. The literature reports reveal the synthesis of organic receptors that can detect analyte through anion induced fluorescence modulations. ${ }^{10,11}$ Most of these organic receptors are fabricated of urea/thiourea group or imidazolium organic cation. ${ }^{12-15}$ The rationale of insertion of urea/thiourea in receptor design lies with the fact that these moieties have a tendency to form hydrogen bonds with anionic analytes. However, on the other hand, it has been observed that the receptors relying on purely hydrogen bonding have limited application while working in aqueous medium due to the competition provided to binding site from water, and moreover hydration of anionic species. ${ }^{16,17,18-20}$ Therefore, the design of a sensor for biomolecules, particularly in an aqueous medium, is still a challenge to inorganic-analytical chemistry. Among these biomolecules, adenosine triphosphate (ATP) is one of the most important anions that contain three negatively charged phosphates. ${ }^{21-23}$ It enzymatically hydrolyzes in the cell to give adenosine diphosphate (ADP), adenosine monophosphate (AMP), and pyrophosphates. ${ }^{24,25}$ Apart from these, it also plays significant role in DNA replication and transcription. Due to the similarity in structure of various competing species, a selective sensor for ATP is the need of the hour. Selectivity can be modulated (improved) by incorporation of hydrogen bonding interaction, ionic interaction, Van der Waal interaction and $\pi-\pi$ interaction into the receptor. ${ }^{26,27}$ Along with these interactions $\mathrm{C}-\mathrm{H}^{\cdots} \pi$ interaction and $\mathrm{C}^{-} \mathrm{H}^{\cdots}$ halide interactions also play a decisive role in the formation of the supramolecular assembly through noncovalent interactions. ${ }^{28-31}$ Likewise, $\pi-\pi$ stacking and hydrogen bonding interaction causes the formation of supramolecular self-assembly which results in aggregation formation or gel formation. ${ }^{32-39}$ Not only supramolecular assembly of metal complex is engaged by noncovalent interactions, their photophysical properties are also directed by these weak interactions in solution as well as in solid state. ${ }^{40-44}$ Therefore, by taking advantages of noncovalent interactions sensitive and 
selective sensor can be developed. Recently Maji et al have developed a selective sensor for $\mathrm{Al}(\mathrm{III})$, that responds toward $\mathrm{Al}(\mathrm{III})$ by fluctuating emission behavior due to change induced by noncovalent interactions. ${ }^{45}$ ATP has adenosine subunit that can interact through $\pi-\pi$ interaction with analyte. ${ }^{46-48}$ Similarly three negatively charged phosphate units have a tendency to interact through ionic interaction. In view of this, Yoon at el had constructed a dipodal receptor that contains pyrene excimer as signaling unit which upon stacking with adenine gave change in emission. ${ }^{49}$ The imidazolium unit conjugated to pyrene act as a phosphate ion receptor. The sensor showed ratiometric sensing of ATP, however, some analytes such as AMP and ADP also show some interference. Kataev at el have synthesized two copper complexes labeled with fluorescent coumarin and anthracene units for detection of ATP in an aqueous medium, which shows some interference due to other analytes. ${ }^{50}$ Also, some binuclear complexes have been developed for sensing of ATP, AMP and pyrophosphates. The two phosphate units coordinate with two different zinc ions, resulting in a change in photophysical properties of the receptor.

In the present work, we have synthesized 1,2 disubstituted fluorescent labeled benzimidazole derivatives (Figure S1) and their complexes with zinc ion. Particularly, zinc ion was chosen due to its $\mathbf{d}^{\mathbf{1 0}}$ configuration, which resists the loss of fluorescence upon complexation due to non-availability of open shell effect. The complexes $\mathbf{R} \mathbf{2}$ and $\mathbf{R 3}$ contain two halide ion and one solvent molecule which can be easily replaced by some strong field ligand. The most interesting features of these complexes are their differences in noncovalent interactions; resulting from a change in aromatic unit attached with benzimidazole moiety. These complexes have the ability to interact with analyte through ionic interaction as well as $\pi-\pi$ stacking. Due to the dual interaction of analyte, ratiometric sensing can be achieved. The ratiometric sensors are more reliable than simply "on-off" fluorescence sensors because the ratiometric behavior is independent from environmental factors, such as temperature, concentration, slit width and scan rate. ${ }^{46}$ To the best of our knowledge, the prepared metal complexes of 1,2 disubstituted benzimidazole are the novel and there is no report on disubstituted benzimidazole based sensor for biomolecules. Thus, this system provides a simpler and more effective way to detect ATP than the methods reported in the existing literature. ${ }^{47-49}$ The interesting fact about this work is the formation of metallogel upon interaction of R1 with ATP in THF: water (30:70).

\section{RESULT AND DISCUSSION}


Synthesis and Characterization of Ligand and Metal Complex: The ligand L1 and L2 were prepared by a reported method from our research group. ${ }^{51}$ The ligand $\mathbf{L 3}$ has been synthesized through a condensation reaction between one equivalent of o-phenylenediamine and two equivalent of the corresponding aldehyde in methanol. Characterization of the ligand was achieved using ${ }^{1} \mathrm{H}-\mathrm{NMR},{ }^{13} \mathrm{C}$ NMR, and elemental analysis. ${ }^{1} \mathrm{H}-\mathrm{NMR}$ signal at $5.8 \mathrm{ppm}$ (singlet) confirmed the formation of the product, as this signal corresponds to aliphatic protons, showing intensity for two protons. Also, a number of protons in aromatic region of ${ }^{1} \mathrm{H}-\mathrm{NMR}$ spectra and number of carbons in ${ }^{13} \mathrm{C}-\mathrm{NMR}$ spectra confirmed the structure of corresponding ligands. The complexes of ligand L1-L3 with zinc ion were prepared in tetrahydrofuran and dimethylformamide (90:10). For complex R1, 2.0 equivalent of $\mathbf{L 1}$ was dissolved in THF along with one equivalent of Zinc bromide. The dark powder was separated out that was dissolved by addition of $10 \%$ of dimethylformamide. The reaction mixture was heated for 3 hours and then cool down to room temperature. The dark brown colored crystals were separated out after 6 hours. The complex $\mathbf{R} 2$ was prepared by reacting one equivalent of $\mathbf{L 2}$ and one equivalent of Zinc chloride in THF: DMF (90:10). Similarly, complex R3 was prepared using similar method, the one which was used for the synthesis of $\mathbf{R 2}$. All of the complexes were characterized using elemental analysis and infrared spectroscopy. For the final validation of structures, single crystal structure was obtained, showing 2:1, 1:1, and 1:1 composition of ligand: metal complexes, respectively for L1, L2 and L3.

\section{X-Ray Structure Determination}

Crystal suitable for $\mathrm{X}$-ray diffraction studies were isolated by slow evaporation technique in THF: DMF. The crystals $\left[\{\mathrm{L} 1\} \mathrm{ZnBr}_{2}\right](\mathbf{R} 1),\left[\{\mathrm{L} 2(\mathrm{DMF})\} \mathrm{ZnCl}_{2}\right](\mathbf{R 2})$ and $\left[\{\mathrm{L} 3(\mathrm{DMF})\} \mathrm{ZnBr}_{2}\right](\mathbf{R 3})$ aree quite stable, therefore data of all crystals were collected at room temperature. Data collection and unit cell parameters are shown in table 1, whereas the list of bond length and bond angles is presented in table $\mathbf{S 1}$ to $\mathbf{S 9}$ respectively in the supporting information. ${ }^{52}$ The structure was solved with the olex 2. solve $^{52}$ structure solution program using Charge Flipping and refined with the olex2.refine refinement package using Gauss-Newton minimization. Interestingly, upon changing the number of rings from benzene to naphthalene and pyrene, packing of the crystals changes dramatically. The angle of the plane between benzimidazole ring and another aromatic subunit greatly affect the absorbance and emission profile of complexes. Arguably, the most important feature of this paper concerns observation of the difference in 
non-covalent interaction resulting from a change in aromatic unit attached with benzimidazole moiety, which plays a decisive role in supramolecular packing as well as photophysical properties.
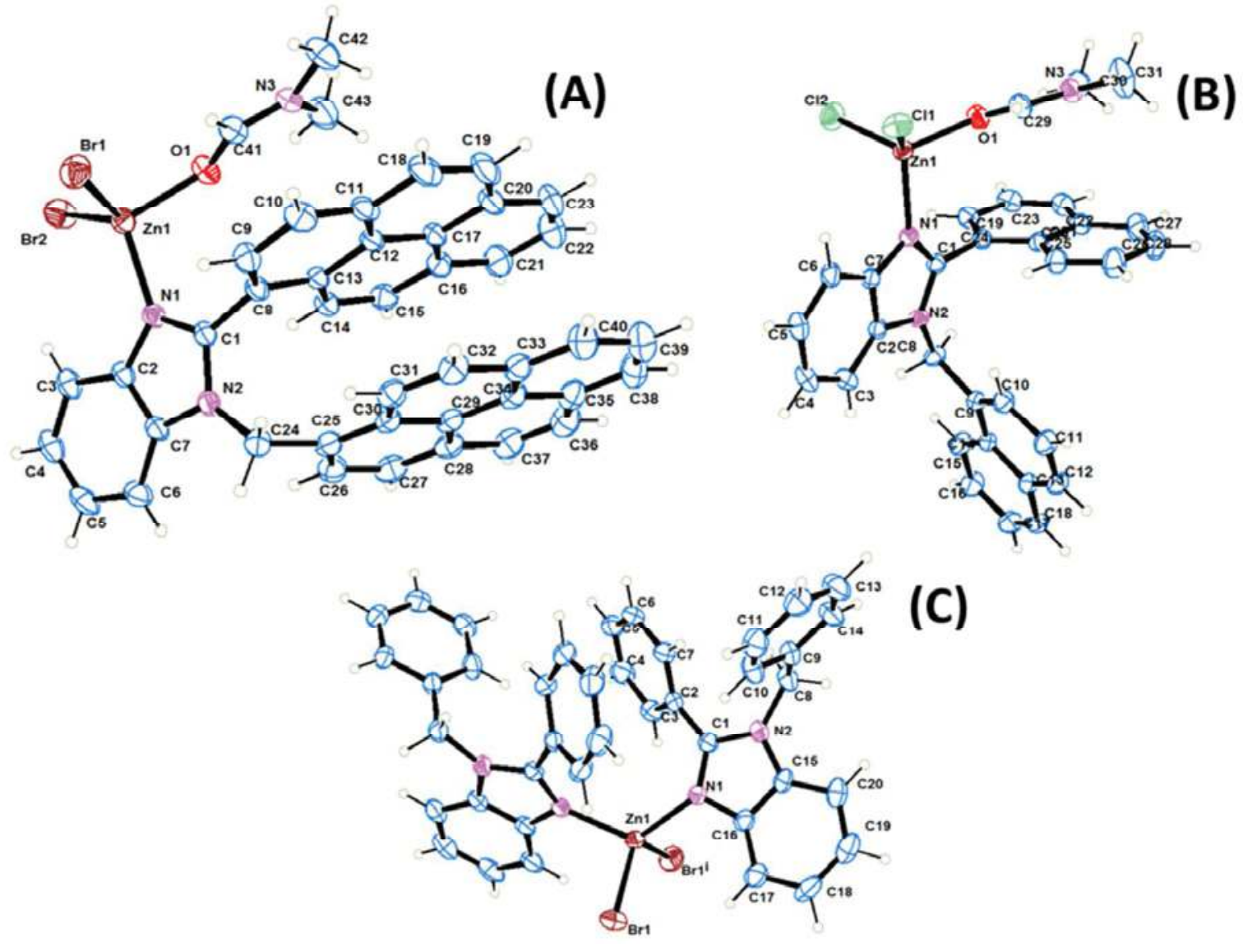

Figure 1: Crystal structure of complex (A) R1, (B) R2, and (C) $\mathbf{R 3}$ with $\mathbf{4 0} \%$ probability thermal ellipsoids.

Table 1: Crystal data and structure refinement

\begin{tabular}{llll}
\hline CCDC Number & $\mathbf{1 5 2 6 9 6 6}$ & $\mathbf{1 5 2 6 9 6 7}$ & $\mathbf{1 5 2 6 9 6 8}$ \\
\hline Identification code & $(\mathrm{R} 1)$ & $(\mathrm{R} 2)$ & $(\mathrm{R} 3)$ \\
Empirical formula & $\mathrm{C}_{40} \mathrm{H}_{32} \mathrm{Br}_{2} \mathrm{~N}_{4} \mathrm{Zn}$ & $\mathrm{C}_{31} \mathrm{H}_{27} \mathrm{Cl}_{2} \mathrm{~N}_{3} \mathrm{OZn}$ & $\mathrm{C}_{43} \mathrm{H}_{31} \mathrm{Br}_{2} \mathrm{~N}_{3} \mathrm{OZn}$ \\
Formula weight & 793.93 & 593.88 & 830.95 \\
Temperature/K & 298.0 & 298.0 & 298.0 \\
Crystal system & monoclinic & monoclinic & Triclinic \\
Space group & $\mathrm{C} 2 / \mathrm{c}$ & $\mathrm{P} 2{ }_{1} / \mathrm{c}$ & $\mathrm{P}-1$ \\
$\mathbf{a} / \AA$ & $19.0112(11)$ & $11.6647(4)$ & $9.0618(3)$ \\
$\mathbf{b} / \AA$ & $10.6875(5)$ & $13.5988(4)$ & $13.0320(5)$ \\
$\mathbf{c} / \AA$ & $18.8991(12)$ & $17.5829(6)$ & $16.0651(6)$ \\
$\boldsymbol{\alpha} /{ }^{\circ}$ & 90 & 90 & $100.320(2)$ \\
$\boldsymbol{\beta} /{ }^{\circ}$ & $116.307(6)$ & $94.2986(10)$ & $105.531(2)$ \\
$\boldsymbol{\gamma}^{\circ}$ & 90 & 90 & $98.173(2)$ \\
$\mathbf{V o l u m e} / \AA^{\mathbf{3}}$ & $3442.3(4)$ & $2781.26(16)$ & $1761.79(11)$ \\
$\mathbf{Z}$ & 4 & 4 & 2 \\
$\boldsymbol{\rho}_{\text {calc }} \mathbf{g} / \mathbf{c m}^{\mathbf{3}}$ & 1.5318 & 1.4182 & 1.5663 \\
\hline
\end{tabular}




\begin{tabular}{|c|c|c|c|}
\hline $\mathbf{F ( 0 0 0 )}$ & 1599.5 & 1226.8 & 835.8 \\
\hline Crystal size $/ \mathbf{m m}^{3}$ & $0.5 \times 0.4 \times 0.4$ & $0.5 \times 0.4 \times 0.4$ & $0.28 \times 0.2 \times 0.16$ \\
\hline Radiation & Mo K $\alpha(\lambda=0.71073)$ & Mo $K \alpha(\lambda=0.71073)$ & $\operatorname{Mo~K\alpha }(\lambda=0.71073)$ \\
\hline $\begin{array}{l}2 \Theta \text { range for data } \\
\text { collection/ }{ }^{\circ}\end{array}$ & 4.5 to 56.86 & 4.6 to 56.54 & 4.68 to 56.62 \\
\hline Independent reflections & $\begin{array}{l}4308\left[\mathrm{R}_{\text {int }}=0.1005,\right. \\
\left.\mathrm{R}_{\text {sigma }}=0.0884\right]\end{array}$ & $\begin{array}{l}6886\left[\mathrm{R}_{\text {int }}=0.0430,\right. \\
\left.\mathrm{R}_{\text {sigma }}=0.0415\right]\end{array}$ & $\begin{array}{l}8730\left[\mathrm{R}_{\text {int }}=0.0474,\right. \\
\left.\mathrm{R}_{\text {sigma }}=0.0467\right]\end{array}$ \\
\hline Data/restraints/parameters & $4308 / 0 / 212$ & $6886 / 0 / 344$ & $8730 / 0 / 452$ \\
\hline Goodness-of-fit on $F^{2}$ & 1.004 & 0.966 & 1.042 \\
\hline Final $R$ indexes $[I>=2 \sigma(I)]$ & $\begin{array}{l}\mathrm{R}_{1}=0.0585, \mathrm{wR}_{2}= \\
0.1419\end{array}$ & $\begin{array}{l}\mathrm{R}_{1}=0.0416, \mathrm{wR}_{2}= \\
0.1207\end{array}$ & $\begin{array}{l}\mathrm{R}_{1}=0.0407, \mathrm{wR}_{2}= \\
0.0748\end{array}$ \\
\hline Final $R$ indexes [all data] & $\begin{array}{l}\mathrm{R}_{1}=0.1516, \mathrm{wR}_{2}= \\
0.1869\end{array}$ & $\begin{array}{l}\mathrm{R}_{1}=0.0769, \mathrm{wR}_{2}= \\
0.1453\end{array}$ & $\begin{array}{l}\mathrm{R}_{1}=0.0855, \mathrm{wR}_{2}= \\
0.0884\end{array}$ \\
\hline
\end{tabular}

\section{Effect of Aromatic Subunit Attached with Benzimidazole on Packing of Complexes}

The complex R1 was crystallized in triclinic crystal system with space group P-1. As shown in the crystal structure (Figure 1), two monodentate ligands form a mononuclear complex containing zinc in a tetrahedral geometry. Another two coordination sites of tetrahedral geometry are occupied with bromide ion, which also stabilizes the +2 oxidation state of $\mathrm{Zn}(\mathrm{II})$. Five different $\mathrm{C}-\mathrm{H}^{\cdots} \pi$ interactions gripped different monomeric units into a supramolecular architecture. Only $\mathrm{C}-\mathrm{H}^{\cdots} \pi$ interactions were found involved in the construction of the 3-D supramolecular network. Upon replacement of benzene ring into naphthalene ring in complex R2, packing of complex completely changed. Instead of two ligands, only one ligand can coordinate with zinc ion in $\mathbf{R 2}$ and fourth coordination site was occupied by solvent molecule (Dimethylformamide). As shown in Figure 2, the two monomeric units of complex $\mathbf{R} 2$ hold together through $\mathrm{C}-\mathrm{H}^{\cdots} \mathrm{H}-\mathrm{C}$ interaction, whereas chloride ion interacts with various hydrogens (Methylene and aromatic) to extend this 3-D supramolecular architecture. This kind of noncovalent interactions highly depends upon the aromatic $\pi$ surface, electron rich or electron deficient aromatic system. ${ }^{53,54}$ The complex $\mathbf{R 3}$ contained highly conjugated pyrene ring system that has completely different kind of noncovalent interactions involving $\pi-\pi$ stacking between pyrene rings along with $\mathrm{C}-\mathrm{H}^{\cdots} \pi$ and $\mathrm{Br}^{\cdots} \mathrm{H}$ interactions (Figure 3). These weak noncovalent interactions are highly sensitive toward microenvironment and play a decisive role in photophysical properties; ${ }^{55-61}$ therefore there are reasonable possibilities to develop the sensors for biomolecules. Till date, many metal-organic complexes have been reported with $\pi-\pi$ stacking interactions between pyrene ring or with another fluorophores. ${ }^{62-64}$ However few reports are available where such kind of complexes are used for molecular recognition. ${ }^{65,66}$ Therefore to explore the possibility to interact these metal 
complexes with some particular analytes, molecular recognitions studies were performed with various anionic species using fluorescence spectroscopy. We expected that these specific orientations of metal complexes would introduce interesting photophysical properties that could be altered by the interaction with specific analytes.
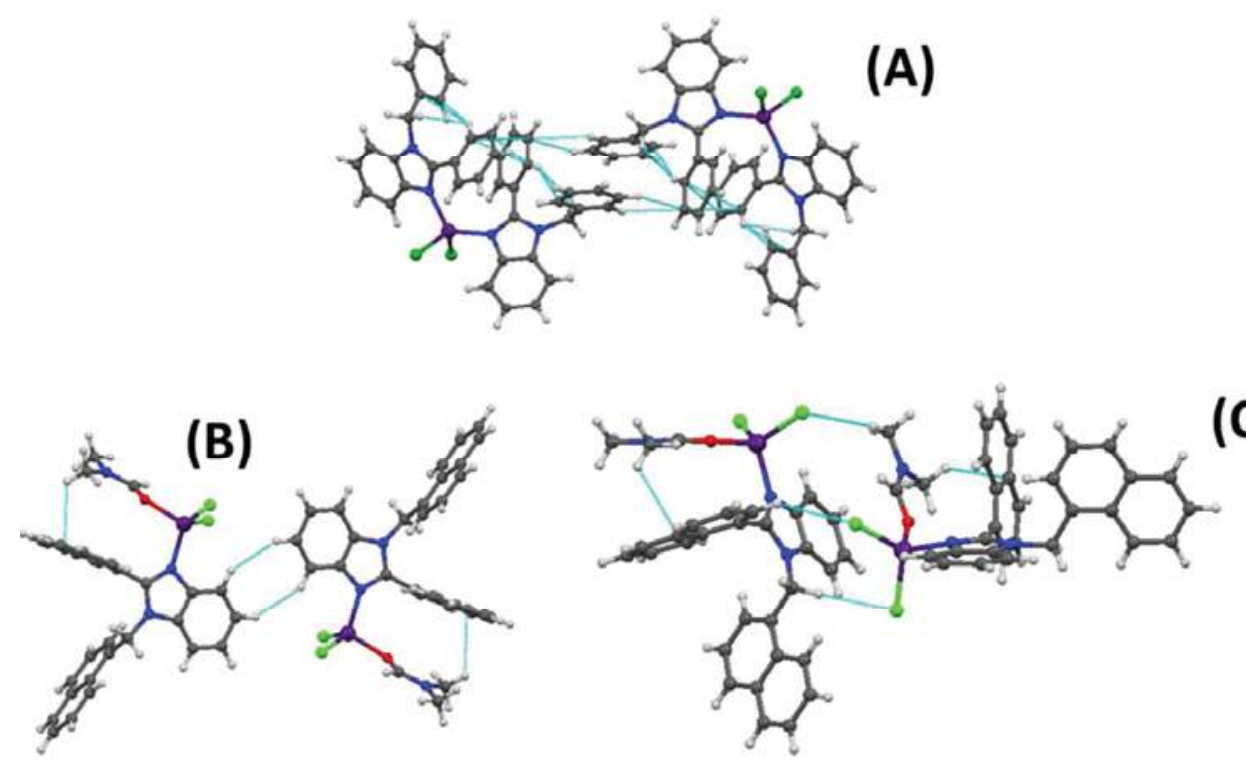

(C)

(D)
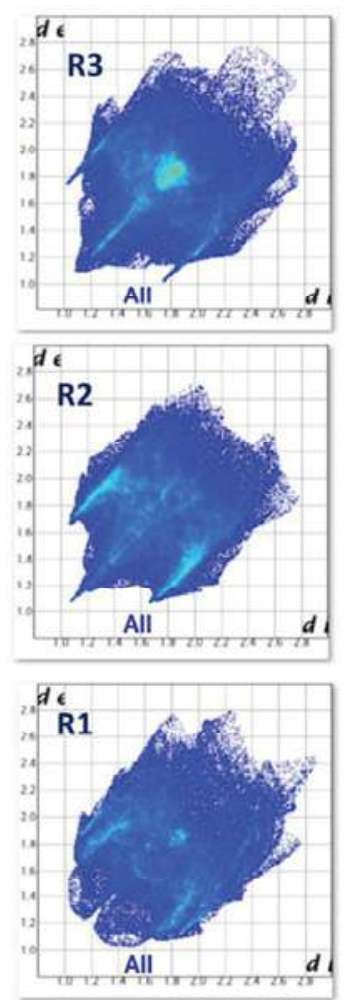
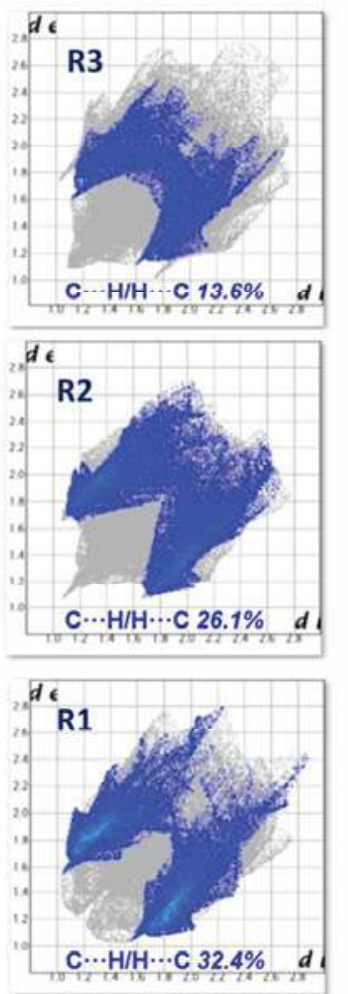
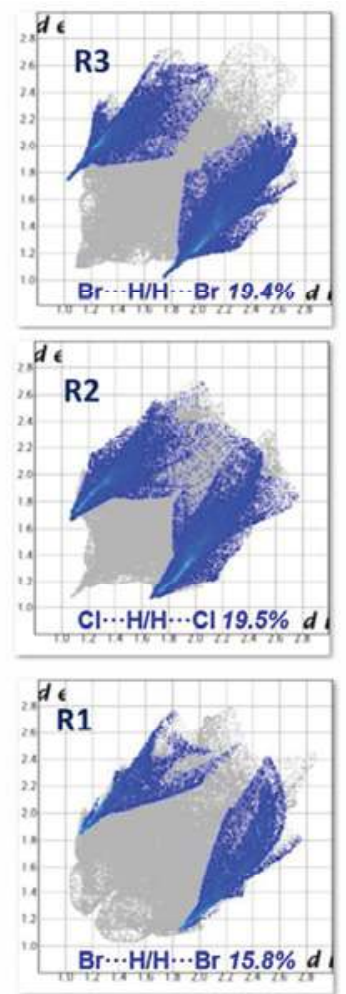
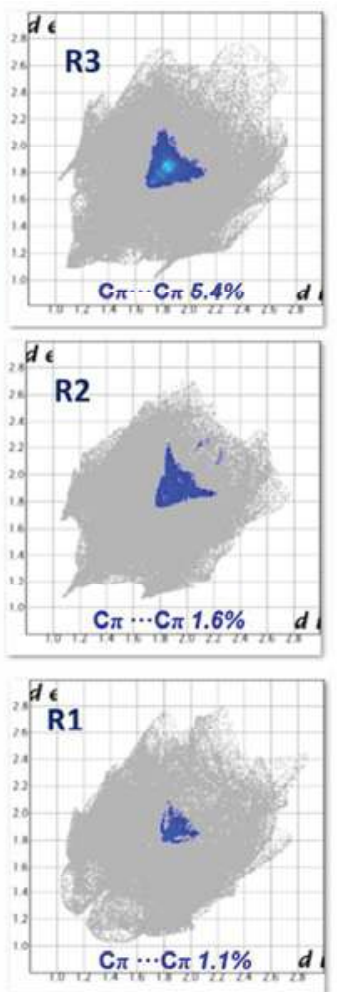
Figure 2: (A) Structural details of R1, showing various non covalent interactions (B) Structural details of R2, showing various non covalent interactions $(\mathrm{C}) \mathrm{C}-\mathrm{H} \cdots \mathrm{Cl}$ interaction leads to the formation of polymeric structure in the $\mathbf{R} 2$ complex. (D) Fingerprint plots of the title complex: full and resolved into all, $\mathrm{C} \cdots \mathrm{H} / \mathrm{H} \cdots \mathrm{C}, \mathrm{X} \cdots \mathrm{H} / \mathrm{H} \cdots \mathrm{X}$ and $\mathrm{C} \pi \cdots \mathrm{C} \pi$ contacts showing the percentages of contacts contributed to the total Hirschfeld surface area of molecules.

To clarify the nature of intermolecular interactions, the Hirschfeld surface of the molecular moiety was analyzed which provides fingerprint of the interactions involved at intermolecular level. Hirshfeld surface mapped with $d_{\text {norm }}$ takes various parameters into consideration to calculate normalized contact distance We have discovered that the major proportion of the Hirshfeld surface was compromised by $\mathrm{C} \cdots \mathrm{H} / \mathrm{H} \cdots \mathrm{C}$ interactions in each complex that were the highest in case of the $\mathbf{R} \mathbf{1}$ complex. The portion of the Hirshfeld surface corresponding to $\mathrm{C} \pi \cdots \mathrm{C} \pi$ increases as the number of aromatic rings increased from benzene to naphthalene and further to pyrene. These results validate the ability of pyrene ring for the formation of supramolecular self-assembly through $\pi \cdot \pi$ stacking.

Photophysical Properties of Complexes R1 and R2: Initially, spectroscopic properties of ligand L1 $(10 \mu \mathrm{M})$ responding to $\mathrm{Zn}(\mathrm{II})$ were examined in HEPES buffer system $(\mathrm{pH}=7.0,1 \mathrm{mM}, \mathrm{DMF} / \mathrm{Water}$ 30:70). Absorbance spectra of $\mathbf{L 1}$ have shown two absorbance band at $225 \mathrm{~nm}$ and $290 \mathrm{~nm}$ corresponding to $\pi$ to $\pi^{*}$ and $n$ to $\pi^{*}$ transitions, respectively. As displayed in Figure S2, absorbance intensity of ligand $\mathbf{L 1}$ changes significantly upon addition of zinc ion. ${ }^{67,68}$ To find out the molar excitation coefficient, absorbance was recorded by successive addition of $\mathrm{Zn}$ (II) to the solution of $\mathbf{L 1}$, L2, and L3. The molar absorbance coefficient was measured and summarized in Table 2. The modulation of molar absorbance coefficient can be seen upon substitution of a new aromatic ring to ligand L1. The emission spectra of the ligand show emission maxima at around $433 \mathrm{~nm}\left(\lambda_{\mathrm{ex}}\right.$ at $290 \mathrm{~nm}$, scan rate 200 and slit widths $=10 \mathrm{~nm}$ ). As the concentration of zinc ion in L1 solution rises, the emission intensity at $430 \mathrm{~nm}$ increases which is related to the cancellation of the PET mechanism caused through the lone pair of the nitrogen donor (Figure S3). The solid state structure clarify that ligand L1 coordinates with zinc ion in 2:1 (L1: $\left.\mathrm{Zn}^{2+}\right)$ ratio. Further to find out the stoichiometry of complex formation in a solution state, measurement were performed through Job's plot method. A nonlinear fitting showed a maximum value at 0.66 which allows us to conclude that alike solid state structure, in solution state stoichiometry complex remain same 2:1 (L1: $\mathrm{Zn}^{2+}$ ). Further, binding constant of complexation was calculated using the Benesi-Hildebrand method. The inverse of the concentration of zinc ion was plotted against the inverse of change in emission intensity. The slope and intercept of the 
curve were determined using a linear regression method, which allowed determining the binding constant equal to $1.4 \times 10^{5} \mathrm{M}^{-1}$. To check the working $\mathrm{pH}$ for binding studies, emission profiles were recorded at different $\mathrm{pH}$, suggesting that receptor stabilizes at $\mathrm{pH} 4$ to $9 \mathrm{pH}$. At basic $\mathrm{pH}$, zinc hydroxide was formed and thus causing decomplexation and loss of fluorescence due to restore of PET channel. Therefore all binding experiments were performed at $\mathrm{pH}$ 7.5.

The absorbance spectra of ligand $\mathbf{L} \mathbf{2}$ has shown three absorbance maxima at 215nm, $245 \mathrm{~nm}$ and 295 $\mathrm{nm}$ (Figure S4), that correspond to the presence of two different chromophores in the system. Upon addition of zinc chloride, the absorbance intensity of the receptor $(\sim 215 \mathrm{~nm})$ changes significantly. The emission spectra of ligand $\mathbf{L 2}$ were taken in DMF: water (30:70) $\left(\lambda_{\text {ex }}\right.$ at $290 \mathrm{~nm}$, scan rate 200 and slit widths $=10 \mathrm{~nm}$ ). The emission spectrum of the complex has shown two peaks at $425 \mathrm{~nm}$ and $550 \mathrm{~nm}$ (Figure S5). As the concentration of zinc ion increases in a solution of complex R2, fluorescence intensity at $425 \mathrm{~nm}$ increases significantly whereas little enhancement was observed at $550 \mathrm{~nm}$. The loss of emission due to photo induced electron transfer was inhibited through the coordination of lone pair of benzimidazole with $\mathrm{Zn}$ (II). For R1, stoichiometry and binding constant of complex in solution state were calculated using Job's plot and Benesi-Hildebrand curve. The stoichiometry of complex found to be 1:1 which perfectly matches that of the solid state structure and the binding constant was found to be $6.89 \times 10^{4} \mathrm{M}^{-1}$.

Binding Studies of Complexes R1 and R2 with Anionic Species: Due to the different electronic arrangement and orientation, three metal complexes offer anion binding pattern; which is unique to the structure of receptor with anionic species. The fluorescence intensity of each complex was recorded in presence of anions $\left(\mathrm{F}^{-}, \mathrm{Cl}^{-}, \mathrm{Br}^{-}, \mathrm{I}^{-}, \mathrm{CH}_{3} \mathrm{COO}^{-}, \mathrm{NO}_{3}{ }^{-}, \mathrm{H}_{2} \mathrm{PO}_{4}^{-}, \mathrm{P}_{2} \mathrm{O}_{7}{ }^{4-}, \mathrm{SO}_{4}{ }^{2-}\right)$ and ATP, AMP, and ADP. The complex R1 showed enhancement in emission intensity upon interaction with ATP along with some interference with AMP and phosphate (Figure S6-S7). This enhancement in emission intensity attributes toward replacement of bromide with phosphate ion. Zinc ion has a tendency to bind strongly with a phosphate ion, ${ }^{69,70}$ while the orientation of a complex also provides the selectivity for a particular analyte. Binding studies of complex $\mathbf{R} 2$ was performed using fluorescence spectroscopy with various anionic species (Figure S8-S9). Similarly for the complex R1, the studies also show fluorescence enhancement with different phosphate species. As shown in Figure S10, ATP showed maximum fluorescence enhancement among investigated analystes. The stoichiometries of $\mathbf{R} 1$ and $\mathbf{R} 2$ complexes 
with ATP were evaluated using Job's Plot, which indicates the formation of a 1:1 complex between $\mathbf{R 2}$ and ATP. The major drawback of the $\mathbf{R 2}$ sensor was its non-specificity because it also shows emission enhancement with other phosphate ions (Figure S11). Therefore it is not suitable for real time determination of ATP.

Table 2: Photophysical properties of ligands and metal complexes

\begin{tabular}{|l|l|l|l|l|l|l|l|l|}
\hline & $\lambda_{\text {abs }}(\mathrm{nm})$ & $\varepsilon_{0}\left(\mathrm{~L} \mathrm{~mol}^{-1} \mathrm{~cm}^{-1}\right)$ & $\lambda_{\text {em }}(\mathrm{nm})$ & $\lambda_{\text {ex }}(\mathrm{nm})$ & $\begin{array}{l}\text { Quantum } \\
\text { Yield }\end{array}$ & $\tau(\mathrm{ns})$ & $K_{r}\left(\mathrm{x}^{8} 0^{8} \mathrm{~s}^{-1}\right)$ & $K_{n r}\left(\mathrm{x} 10^{7} \mathrm{~s}^{-1}\right)$ \\
\hline L1 & 220,290 & $4.42 \times 10^{4}$ & 433 & 220 & 0.31 & 1.1569 & 3.45 & 5.64 \\
& & & & 290 & 0.38 & & & \\
\hline L2 & 245,290 & $4.81 \times 10^{4}$ & 427,546 & 245 & 0.39 & 1.2256 & 3.67 & 4.67 \\
& & & & 290 & 0.44 & & & \\
\hline L3 & $247,277,329$, & $5.62 \times 10^{4}$ & $410,430,472$ & 247 & 0.52 & 2.1256 & 2.67 & 2.10 \\
& 346 & & & 277 & 0.53 & & & \\
& & & & 329 & 0.55 & & & \\
\hline R1 & 225,290 & $4.65 \times 10^{4}$ & 433 & 225 & 0.48 & 1.6856 & 3.38 & 2.88 \\
& & & & 390 & 0.55 & & & 2.16 \\
\hline R2 & 242,289 & $4.85 \times 10^{4}$ & 427,546 & 242 & 0.51 & 1.9452 & 3.11 & 7.74 \\
& & & & 290 & 0.59 & & & \\
\hline R3 & $248,277,330$, & $6.61 \times 10^{4}$ & $410,430,472$ & 247 & 0.73 & 3.1436 & 2.45 & \\
& 345 & & & 277 & 0.75 & & & \\
& & & & 329 & 0.75 & & & \\
\hline
\end{tabular}

Photophysical Properties of Ligand L3 and Complex R3: The absorption and emission spectra of all complexes were recorded in DMF: $\mathrm{H}_{2} \mathrm{O}$ and the electronic absorption spectra of ligands and complexes are shown in Figure S12. The ligand 3 exhibited strong absorption bands at $248 \mathrm{~nm}, 277 \mathrm{~nm}, 330 \mathrm{~nm}$ and $345 \mathrm{~nm}$ (Figure S12). This is due to the presence of two pyrene sub-groups in ligand L3, four different absorption bands appeared. One pyrene ring is directly conjugated with benzimidazole ring whereas another ring is attached with benzimidazole through a methylene group. The conjugated pyrene group should absorb at a higher wavelength, therefore peaks at $277 \mathrm{~nm}$ and $345 \mathrm{~nm}$ are due to $\pi-\pi^{*}$ and $\mathrm{n}-\pi^{*}$ transitions of conjugated pyrene ring. The peaks at $248 \mathrm{~nm}$ and $330 \mathrm{~nm}$ correspond, respectively to $\pi-\pi^{*}$ and $n-\pi^{*}$ transitions of pyrene ring attached with a methylene group. The emission spectra of ligand L3, taken in DMF:water (30:70) $\left(\lambda_{\mathrm{ex}}\right.$ at $345 \mathrm{~nm}$, scan rate 200 and slit widths $\left.=10 \mathrm{~nm}\right)$, has shown four emission maxima at $380 \mathrm{~nm}, 410 \mathrm{~nm}, 440 \mathrm{~nm}$ and $470 \mathrm{~nm}$. Here emission peaks at $410 \mathrm{~nm}$ and $470 \mathrm{~nm}$ correspond to monomer and excimer state ( $\pi-\pi$ stacking) of the receptor, respectively. It is interesting that upon addition of $\mathrm{Zn}(\mathrm{II})$ ion, the fluorescence intensity of receptor increases significantly. 
This large enhancement in emission intensity has been rationalized by the cancellation of the Photoinduced Electron Transfer mechanism. On complexation, the lone pair of benzimidazole ring causes the fluorescence quenching due to the PET phenomenon transferred to the zinc ion. However, the emission intensity at $470 \mathrm{~nm}$ enhanced due to the formation of excimers. To confirm the binding of $\mathrm{Zn}$ (II) with ligand $\mathbf{L 3}$, the titration was performed by successive addition of zinc ion into $10 \mu \mathrm{M}$ solution of complex L3. As shown in figure 2a, the orientation of ligand $\mathbf{L 3}$ changes on complexation with zinc ion in such way that all the pyrene rings got stacked and gave strong excimer emission band at $470 \mathrm{~nm}$. The binding constant for L3-Zn(II) complex calculated using Benesi-Hildebrand method. A graph has plotted between inverse of concentration of analyte and inverse of change in fluorescence (Figure S12). The binding constant has calculated from intercept and slope of the curve, which has found to be $7.34 \times 10^{4}$. 
(A)

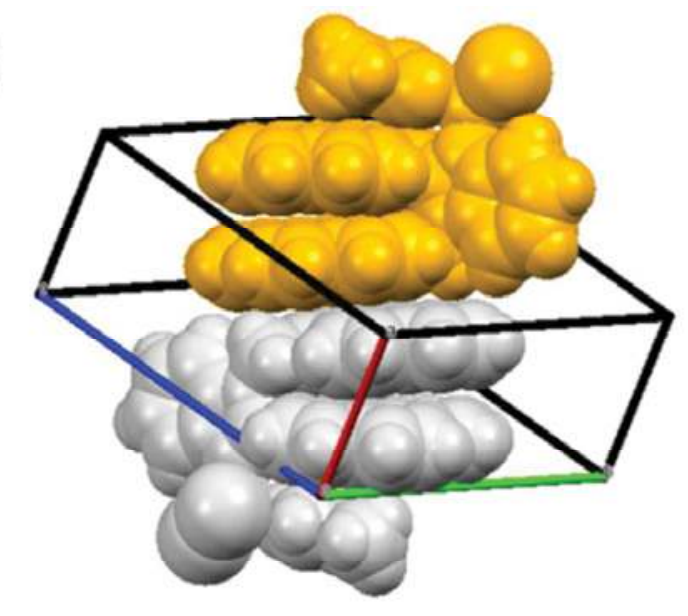

(B)

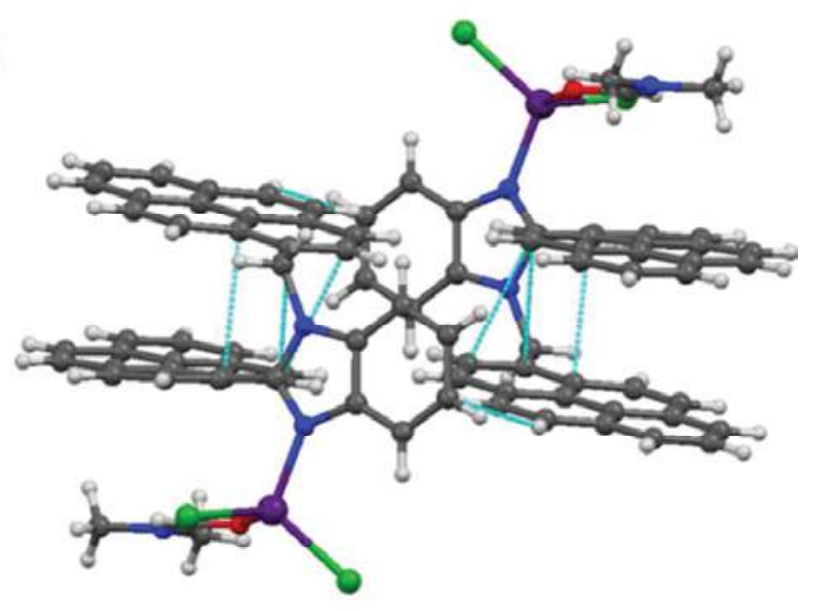

(C)

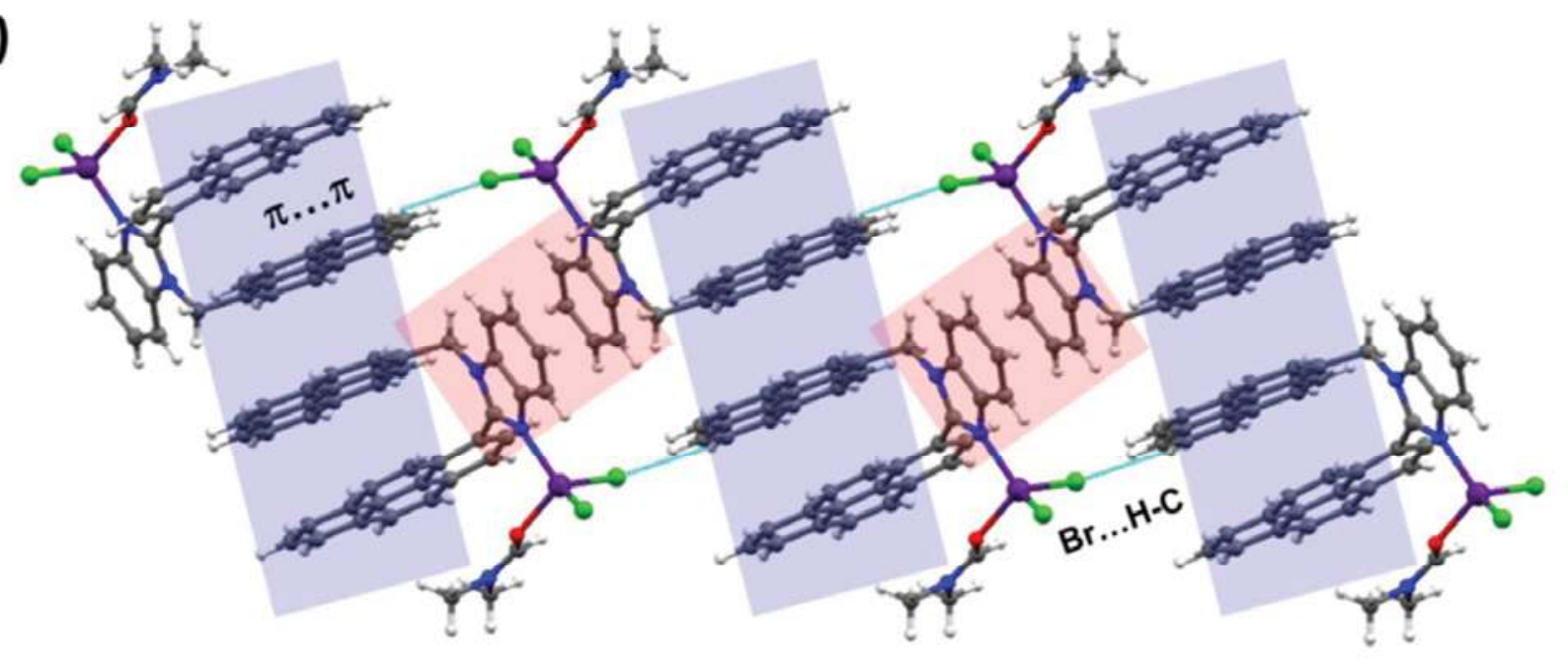

Figure 3: Structural details of R3: (a) Interact between two monomers showing in space fill model. (b) Intramolecular $\pi \cdots \pi$ stacking interaction between pyrene rings in the $\mathbf{R} \mathbf{3}$ complex (c) 2D supramolecular layer formed in the ab plane.

\section{Binding Studies of Complex R3 with Anionic Species}

The binding behavior of complex R3 was examined using fluorescence spectroscopy towards various anionic species such as iodide, bromide, chloride, fluoride, nitrate, dihydrogen phosphate, acetate, ATP, AMP, ADP, PPi (Pyrophosphate), NADH (Nicotinamide adenine dinucleotide), etc. Emission spectra of complex R3 were recorded after the addition of $16 \mu \mathrm{M}$ of each analyte (Figure 4) and it was observed that only ATP has shown a significant change in the emission profile of $\mathbf{R} 3$, whereas all other tested anionic species did not affect fluorescence profile of the complex. Interestingly, the emission at $410 \mathrm{~nm}$ 
(monomeric state) enhanced whereas emission due to the excimer state $(470 \mathrm{~nm})$ quenched as the concentration of ATP increases in the solution. This change in emission intensity can be explained on the basis of formation of a R3-ATP complex. Zinc ion coordinate with two bromide ions and one DMF molecule, which can easily replace by the phosphate ion of ATP. Upon replacement of two bromide ions, the fluorescence intensity at $410 \mathrm{~nm}$ increases, however R3-ATP complex alters the $\pi-\pi$ stacking interaction in such a way that luminescence due to the excimer state disappears. To analyze the binding behavior, emission spectra of $\mathbf{R 3}$ were recorded by successive addition of ATP solution (0-16 $\mu \mathrm{M})$. This allowed the ratiometric detection of ATP. The ratio of fluorescence intensity was plotted against the concentration of ATP added. The calibration plot for ATP exhibited a nonlinear regression up to $16 \mu \mathrm{M}$ with an $\mathrm{R}^{2}$ value of 0.9993 (Figure S13) and detection limit of $15 \mathrm{nM}$. To analyze the effect of another ion on detection of ATP, the competitive binding experiments were performed, which showed that none of the interfering ions obstruct the detection of ATP ion. Also, the UV-visible absorbance spectra of the R3 complex were recorded with the addition of ATP in the THF:Water (30:70) solvent system (Fig S15). 

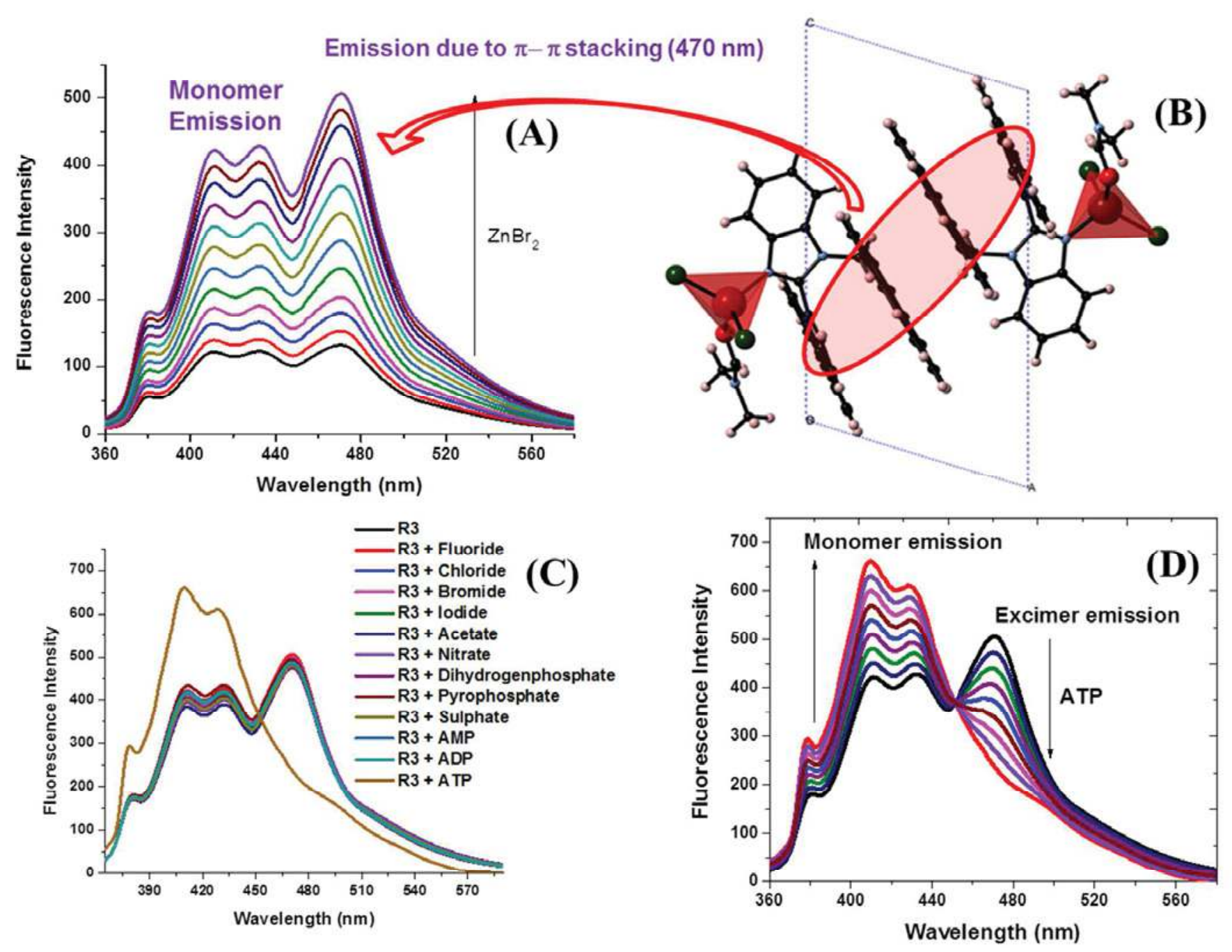

Figure 4: (A) Change in emission profile of ligand $\mathbf{L 3}(10 \mu \mathrm{M})$ upon addition of $15 \mu \mathrm{M}$ of Zinc bromide in DMF: water (30:70) HEPES buffer (B) Packing of complex 3, showing $\pi-\pi$ stacking interaction between pyrene rings. (C) Change in emission profile of complex $3(10 \mu \mathrm{M})$ upon addition of $16 \mu \mathrm{M}$ of various anions in HEPES buffer (DMF: water) (d) Change in emission profile of complex $\mathbf{R 3}$ with successive addition of ATP $(0-16 \mu \mathrm{M})$.

Binding Pattern of ATP with Receptor R3: To find out the stoichiometry of complexation, the Job's plot has constructed. The plot between mole fraction of ATP and [HG], shows maximum value for [HG] at a mole fraction of 0.5 which indicates the 1:1 complexation between $\mathbf{R 3}$ and ATP. The changes induced in excimer and the monomeric emission peak of the receptor $\mathbf{R 3}$ indicate the breakdown of $\pi-\pi$ stacking (Figure 5); also the clear solution converts into a highly viscous liquid which formed a luminescent metallogel upon cooling. Earlier Yoon, et. al. have studied the Sandwich Stacking of Pyrene-Adenine-Pyrene for determination of ATP. Here adenine ring breaks the $\pi-\pi$ stacking in receptor and penetrate between two pyrene rings. ${ }^{49}$ Similar results were obtained from fluorescence 
spectroscopy. Upon addition of ATP, two types of interactions were involved between receptor $\mathbf{R} 3$ and ATP. One is ionic interaction and another is $\pi-\pi$ stacking between Pyrene-Adenine-Pyrene sandwiches. In this way, polymeric structure extended through hydrophobic $\pi-\pi$ stacking interaction was formed causing turbidity in the solution. The ratiometric change in emission (Figure S14) and increase in turbidity indicate that the clear solution changes into the aggregates. To find out the morphology of aggregates formed upon addition of ATP, atomic force microscopic images (AFM) of receptor R3 were taken in the presence of ATP. AFM imaging confirmed the formation of aggregates (Figure 5B-C). Initially, the receptor $\mathbf{R 3}$ was purely crystalline in nature. On the addition of 1.5 equivalent of ATP, aggregates were formed as also confirmed using DLS (Dynamic Light Scattering) experiments. The size of aggregates formed was determined using DLS which showed the particles size distribution in the range of $35 \mathrm{~nm}$ to $40 \mu \mathrm{m}$ (Figure S16). To determine the stoichiometry of complex formation between ATP and complex R3, fluorescence data were utilized to construct Job's plots. The $x$-axis of the Job's plot is labeled as the mole fraction of ATP (Figure S17). The intersection of the two linear portions of the Job's plot gives the mole ratio corresponding to the binding stoichiometry between ATP and R3, which confirmed formation of the 1:1 complex between ATP and $\mathbf{R 3}$. The binding constant $\left(K_{\mathrm{a}}\right)$ of $\mathbf{R 3}$ for ATP was also determined by constructing the Benesi Hildebrand plot; a $K_{\mathrm{a}}$ value of $2.57( \pm 0.04) \times$ $10^{4} \mathrm{M}^{-1}$ was obtained from the slope and intercept of the line (Figure S18).

Gel Formation with the interaction of ATP: All the binding studies were performed in Water: DMF (70:30), while the solution of receptor $\mathbf{R 3}$ turned turbid upon interaction with ATP. Further, we have examined the behavior of receptor R3 with ATP in another solvent system. It was observed that in tetrahydrofuran:water (30:70), the more viscous liquid was formed which turned to metallogel upon cooling for 6 hours. To investigate the morphology of gel, scanning tunneling microscopy images were recorded and it was observed that a polymeric network was formed which quench the excimer fluorescence. As shown below in cartoon diagram, ATP interacts with probe $\mathbf{R} 3$ in such a way that adenosine unit penetrate between two pyrene rings which abolish the $\pi$ - $\pi$ interaction between two pyrene rings and induced new sandwich complex having $\pi-\pi$ stacking between pyrene-adenosinepyrene. Such kind of planar conjugated systems are well known for formation of $\pi$ - $\pi$ stacking induced gel. $^{71-73}$ This supramolecular assembly highly depends upon anionic species, nature of interaction and solvent system. ${ }^{74-77}$ It is interesting that metallogel is formed in THF:Water (30:70), whereas aggregates 
are formed in DMF:Water. Therefore the gel formation is not only selective for anionic species (ATP) but also solvent decide the morphology formed in the solution.

Selectivity of Receptor R3 for ATP: To investigate the interference caused by competing analytes, such as ADP, AMP, PPi, NADH and other anions, we recorded the corresponding fluorescence spectra. It was find out that ADP and AMP show negligible change in monomeric and excimer emission peaks. Similarly, other analytes did not show any significant change in emission profile. As shown in Figure 6, the ratio $\left(\mathrm{I}_{\text {monomer }} / \mathrm{I}_{\text {excimer }}\right)$ for ATP is much larger as compared to other analytes. The above selectivity for ATP can be explained on the basis of the binding pattern. ATP bind with zinc ions through ionic bond by replacing two bromide ions and, similarly, AMP and ADP bind with receptor $\mathbf{R 3}$ through ionic bond. However hydrophobic interaction ( $\pi-\pi$ stacking) plays a crucial role in emission change. Therefore due to the difference in chain length in ATP, AMP and ADP, these analytes behave differently while interacting with receptor R3. For perfect binding or ratiometric sensing, it is necessary that both interactions (ionic and hydrophobic) occur simultaneously, which is possible only in case of ATP. Thus, neither AMP nor ADP shows response to receptor R3 (Figure S19). Further to validate the observation, the powder XRD spectra of complex R3 has recorded and compared with the simulated XRD pattern, which was perfectly superimposed (Figure S24). Then the complex was reacted with ATP and ADP in THF: water, after removing the solvent with the vacuum, the prepared compound has washed with water, to remove the free phosphate species. The broad XRD pattern of R3-ATP revealed the formation of polymeric aggregates, ${ }^{80}$ whereas solid state XRD spectra of R3-ADP was showing sharp peaks, which also have similarity with XRD spectra of R3 complex. To confirm the formation of R3-ATP complex, Raman spectra has recorded. To record the Raman spectra, the crude obtained from the reaction of Zinc complex R3 with ATP, has washed with distilled water to remove the unreacted Adenosine triphosphate ions. The Raman spectra of this crude expressively different pure R3 complex and showing peaks corresponds to Zinc-phosphate bond and Phosphorous-oxygen bonds $\left(725 \mathrm{~cm}^{-1}, 1005 \mathrm{~cm}^{-1}, 1122 \mathrm{~cm}^{-1}\right)$ which confirm the formation of R3-ATP complex (Figure S25). However, ADP ion was showing similar spectra as the complex $\mathbf{R 3}$, reveals that complex R3 is not reactive toward ADP. To confirm the complexation of ATP with complex R3, the chemical characterization of R3 complex and R3-ATP has performed using energy-dispersive X-ray spectroscopy (Figure S26). It revealed that the complex R3 has $\mathrm{Zn}, \mathrm{Br}, \mathrm{C}, \mathrm{N}$ and $\mathrm{O}$; however, the bromide ion disappears upon complexation with ATP. The presence of peak at 2.1 corresponds to phosphorous, which confirmed the replacement of $\mathrm{Br}^{-}$ion with 
phosphate unit of ATP. Whereas, in crude of R3-ADP, the peak corresponds to Br still appear and negligible presence of phosphorous has seen. 

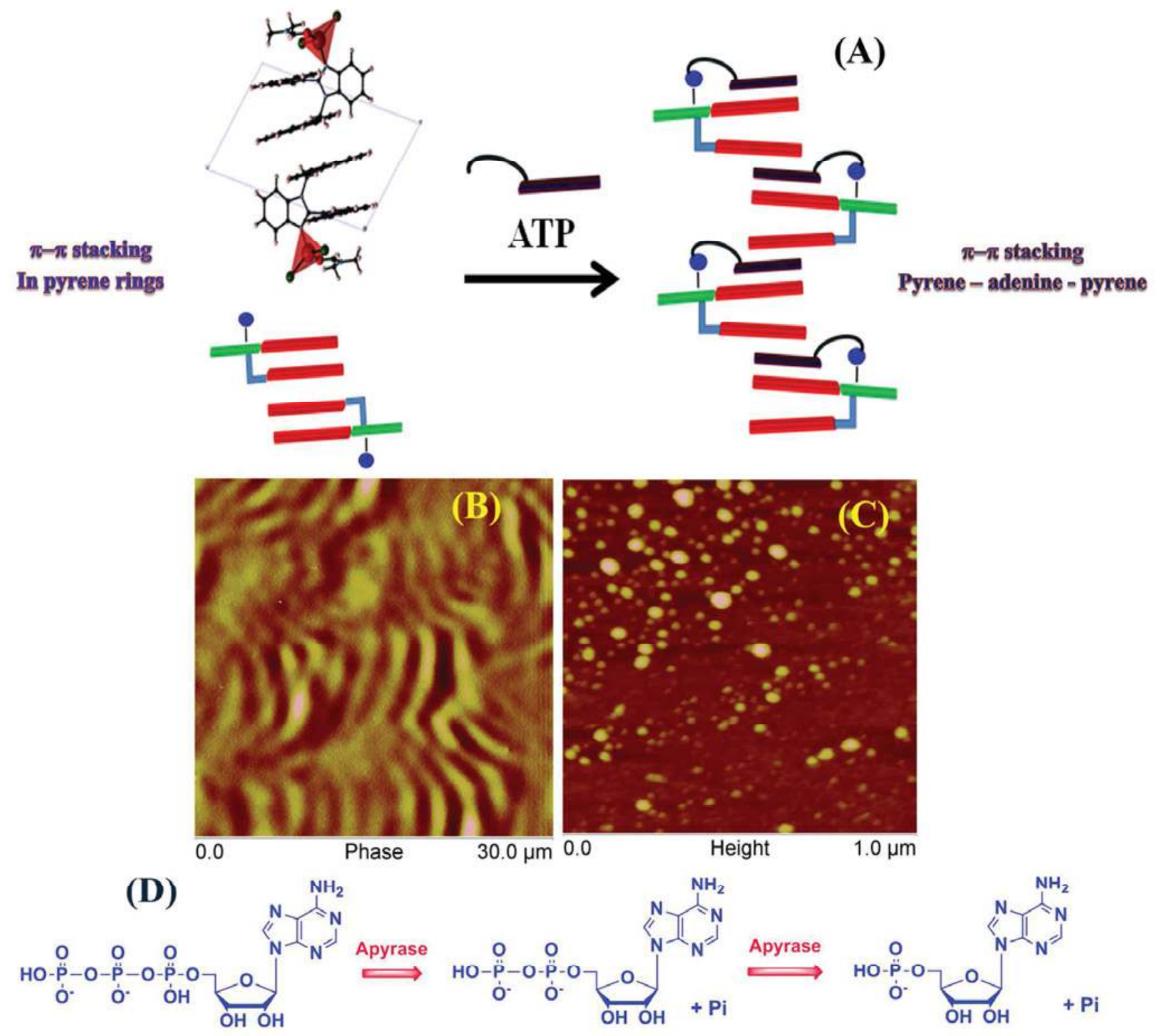

Adenosine triphosphate

Adenosine diphosphate

Adenosine monophosphate
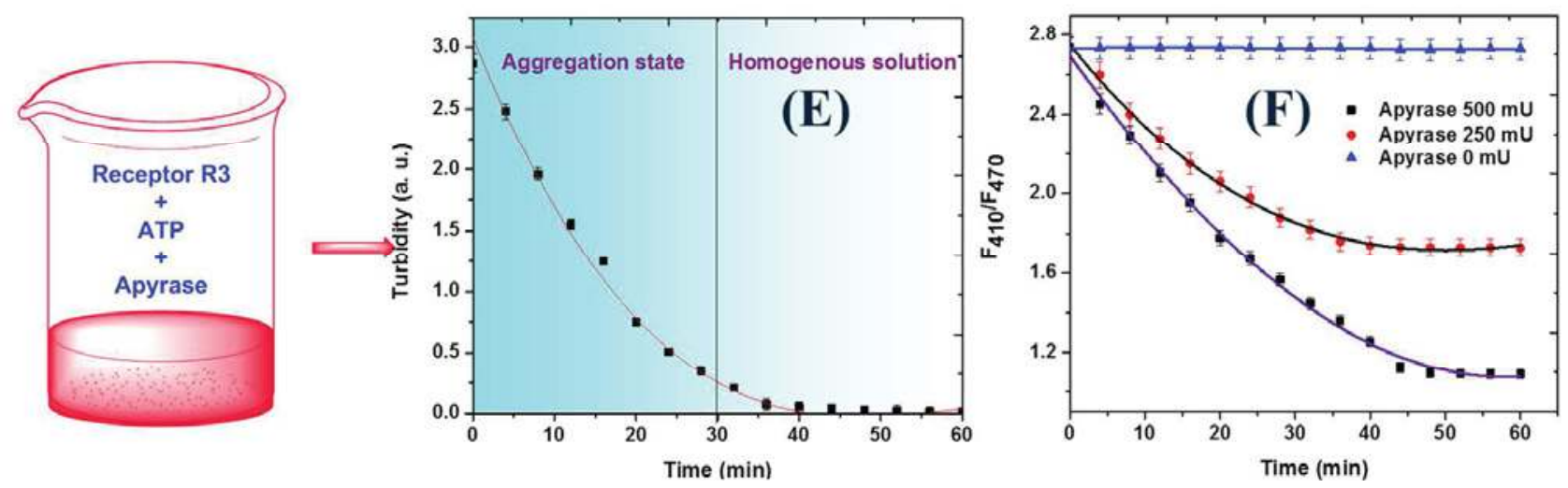

Figure 5: (A) Cartoon diagram of ATP induced gel formation. (B) AFM images of $\mathbf{R 3}$ upon interaction with ATP in THF: water (C) AFM images of R3 upon interaction with ATP in DMF: water (D) The 
reaction showing the hydrolysis of ATP in presence of apyrase enzyme. (E) Change in turbidity of $\mathbf{R 3}+$ ATP solution in DMF: water in presence of apyrase with time. (F) Change in turbidity of R3 + ATP solution in DMF: water in presence of apyrase $(0$ to $250 \mathrm{mU})$ with time.

Biological Applications of Receptor R3: To analyze the response of the receptor to intercellular investigation of ATP, HeLa cells were investigated under a fluorescence microscope for an excitation wavelength of $340 \mathrm{~nm}-380 \mathrm{~nm}$ and an emission wavelength of $435 \mathrm{~nm}-485 \mathrm{~nm}$ for blue fluorescence. For the fluorescence microscopic experiments, HeLa cells were grown in Dulbecco's Modified Eagle's medium (DMEM) using reported protocol. ${ }^{78}$ The cells were divided into two parts. Among these, one part was incubated with $10 \mu \mathrm{M}$ of oligomycin that is well known for its ATP syntheses inhibition activity. Then both parts were exposed to receptor R3 $(20 \mu \mathrm{M})$ for 3 hours. Before the fluorescence measurement, the cells were washed with phosphate buffer solution (PBS). The receptor $\mathbf{R} 3$ was causing a loss in fluorescence in oligomycin part, whereas HeLa cell incubated with only probe R3 show emission in HeLa cells (Figure S20). These experiments showed that receptor R3 is capable to determine ATP in presence of another inorganic phosphate such as AMP and ADP in the intercellular system. Further, the ratiometric emission conversion with ATP was used to explore the probe R3 to study the activity of apyrase enzyme that is well known for hydrolysis of nucleotide triphosphates. Our probe $\mathbf{R 3}$ show ratiometric response only with ATP, therefore upon hydrolysis signature emission profile of R3-ATP complex should disappear. With this in mind, a solution of R3 (20 $\mu \mathrm{M})$, ATP (20 $\mu \mathrm{M})$ and apyrase was prepared at $\mathrm{pH} 6$ and emission profile was recorded after a short interval of time. The curve (Figure 5) shows that in the absence of apyrase, fluorescence intensity $\left(\mathrm{F}_{410 \mathrm{~nm}} / \mathrm{F}_{470 \mathrm{~nm}}\right)$ remains almost unchanged, however in the presence of two different concentrations of apyrase it decreases dramatically, which validate the conversion of ATP into AMP and ADP and finally into phosphates. To explore the mechanism more deeply, the turbidity of the solution was measured with time, which also shows a continuous decreas with time (up to 60 minutes) (Figure 5). Thus, the prepared probe can be used for monitoring the activity of apyrase enzyme. 

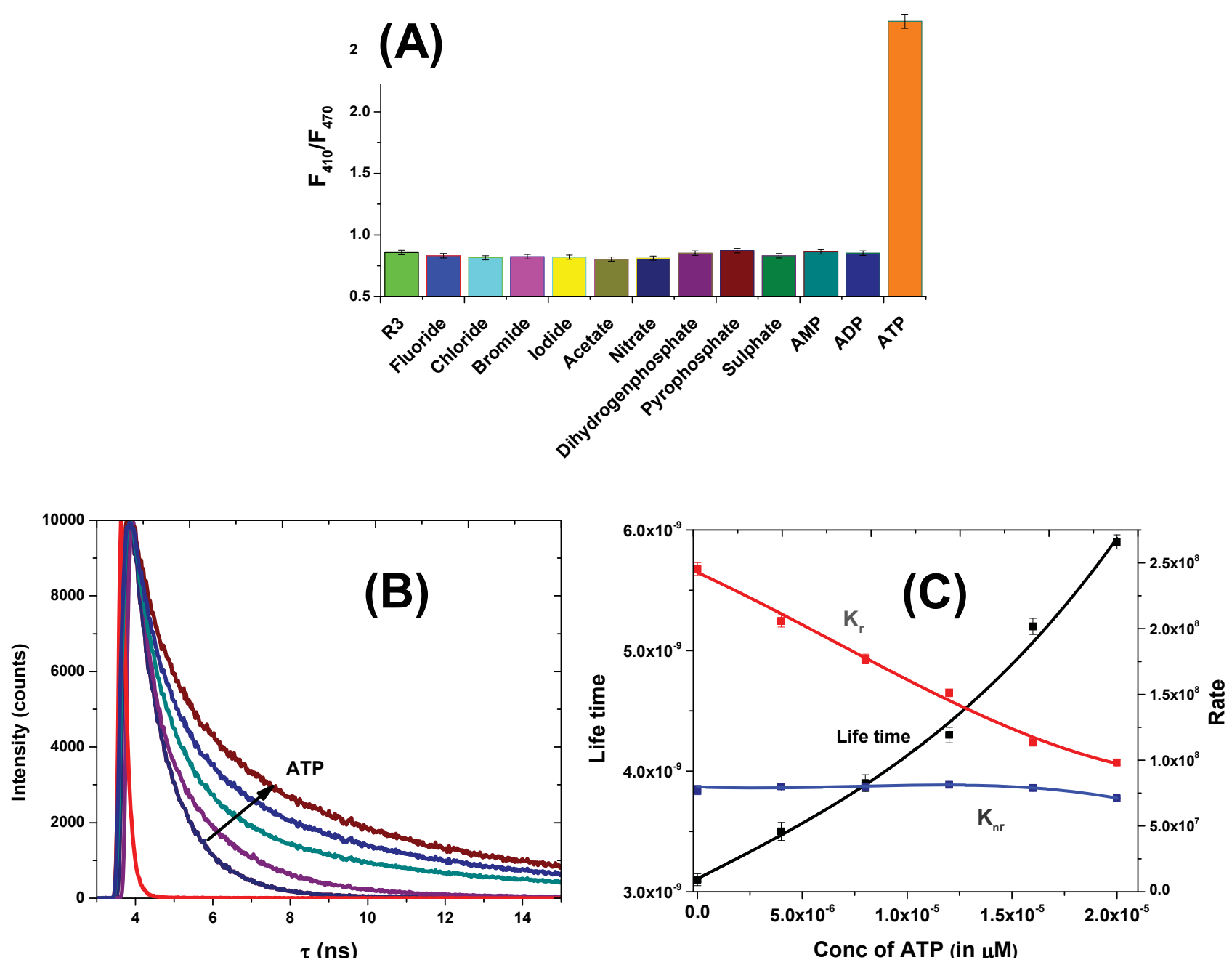

Figure 6: (A) Competiting binding of complex R3 with various anionic species. (B) Change in fluorescence life time of $\mathbf{R 3}$ upon interaction with ATP.

Fluorescence decay time and radiative constant

Fluorescence is perfect nano scale probe as its decay could take place on the nanosecond level. Therefore it is a promising technique to evaluate molecular interactions and changes in a nanoenvironment. To analyze the effect of aggregation on photophysical properties and decay time, time resolved fluorescence spectra were recorded at the wavelength of $472 \mathrm{~nm}$, which enlightens the mechanism of sensing of ATP. Fluorescence quantum yield and life time were determined using time resolved fluorescence and radiative decay constant using the following formulas:

$$
\Phi f=\frac{K r}{K r+K n r} \quad \text { and } \quad \tau=\frac{1}{K r+K n r}
$$


where $\phi_{\mathrm{f}}$ is fluorescence quantum yield, $\tau$ is a life time, $K_{r}$ is radiative decay constant and $K_{n r}$ is nonradiative decay constant.

The rate of radiative decay of the excited state decreases as the concentration of ATP increases in solution, whereas life time of excited state increases. This transformation is due to the formation of aggregates where properties of the excited state are different and lead to an increased life time. ${ }^{79}$ Whereas a decreasing radiative decay constant is attributed to quenching of the excimer emission. We observed a minor change in the nonradiative decay constant upon addition of ATP to the $\mathbf{R 3}$ solution.

\section{Conclusion}

In summary, we have synthesized three zinc complexes tagged with fluorescence moieties that can form a tertiary complex with biologically important phosphates. Upon addition of ATP, the complex R1 showed distinct spectroscopic behavior due to the replacement of bromide ion. The $\mathbf{R} \mathbf{1}$ and $\mathbf{R} \mathbf{2}$ interact only through ionic interaction with phosphates. Therefore, these complexes show emission enhancements with ATP along with some interference of AMP and phosphate. The complex R3 has a tendency to interact through by both $\pi-\pi$ stacking and ionic interaction. It selectively binds with ATP even in the presence of other phosphates. Two types of interactions act differently on emission properties of the complex. Ionic interactions cause enhancement in fluorescence intensity at $410 \mathrm{~nm}$, whereas the $\pi-\pi$ stacking interaction between pyrene and adenosine ring quenches the emission at 470 $\mathrm{nm}$. Thus, the pyrene conjugated complex of Zinc (R3) is capable of detecting ATP ratiometrically with a low detection limit. Furthermore, the complex $\mathbf{R 3}$ was explored for monitoring the activity of Apyrase enzyme during (?) hydrolysis of ATP. The outcome of this work is important for the development of a highly selective ATP sensor using ionic and other non-covalent interactions.

\section{Experimental}

General Information: Ortho-phenylenediamine, aldehydes, and biomolecules (Analytical grade) were procured from Sigma Aldrich and used without further purification. Oligomycin (from Streptomyces diastatochromogenes) and Apyrase enzyme (From Potato) was purchased from Sigma Aldrich. Methanol and tetrahydrofuran were purchased from Merck. The photoluminescence experiments were performed on Perkin Elmer LS-55 instrument at a constant scan speed of 200. For all experiments, excitation and emission slit width was kept $10 \mathrm{~nm} .{ }^{1} \mathrm{H}-\mathrm{NMR}$ and the ${ }^{13} \mathrm{C}-\mathrm{NMR}$ spectrum were recorded 
on Jeol instrument which was operated at $400 \mathrm{MHz}$ for ${ }^{1} \mathrm{H}-\mathrm{NMR}$ and $100 \mathrm{MHz}$ for ${ }^{13} \mathrm{C}-\mathrm{NMR}$. The Single crystal data for three complexes were measured on Bruker X8 APEXIII KAPPA CCD diffractometer at room temperature using graphite monochromatized Mo-K $\alpha$ radiation $(\lambda=0.71073$ $\AA)$. Elemental analyses were carried out using Fisons CHNS analyzers. The morphology of gel was found out on a scanning electron microscope (SEM JEOL JSM-6610LV) using a voltage of $15 \mathrm{KV}$ and Atomic force microscopy (AFM). The particle size of nanoparticles was determined by dynamic light scattering (DLS) using external probe feature of Metrohm Microtrac Ultra Nanotrac particle size analyzers. Fluorescence microscopy of HeLa cells was recorded on Leica fluorescence microscope. Fluorescence life time was calculated from time resolved fluorescence spectroscopy using PicoQuant fluorescence spectrophotometer.

Detail of UV-visible absorbance and Fluorescence Measurements: The stock solution of each ligand $(10 \mu \mathrm{M})$ was prepared in DMF: water (30:70). Similarly, a stock solution of zinc bromide and zinc chloride (each $1 \mathrm{mM}$ ) was prepared in hot distilled water and diluted further as a requirement of the experiment. The solution of various anions as tetra butyl ammonium salt $\left(\mathrm{F}^{-}, \mathrm{Cl}^{-}, \mathrm{Br}^{-}, \mathrm{I}^{-}, \mathrm{CH}_{3} \mathrm{COO}^{-}, \mathrm{NO}_{3}^{-}\right.$ , $\left.\mathrm{H}_{2} \mathrm{PO}_{4}{ }^{-}, \mathrm{P}_{2} \mathrm{O}_{7}{ }^{4-}, \mathrm{SO}_{4}{ }^{2-}\right)(1 \mathrm{mM})$ and ATP (Adenosine triphosphate), AMP (Adenosine monophosphate), and ADP (Adenosine diphosphate) $(1 \mathrm{mM})$ were prepared in distilled water. The $\mathrm{pH}$ of the solution was maintained at 7.0 using $1 \mathrm{mM}$ HEPES buffer solution.

Synthesis of $\mathbf{L} 1$ (1-Benzyl-2-phenyl-1H-benzo[d]imidazole): ${ }^{51}$ In a round bottom flask, the benzaldehyde (2.44 gm, $10 \mathrm{mmol})$ and o-phenylenediamine $(1.08 \mathrm{gm}, 10 \mathrm{mmol})$ was dissolved in $50 \mathrm{~mL}$ of methanol along with $(0.185 \mathrm{gm}, 0.5 \mathrm{mmol})$ of zinc perchlorate. The reaction mixture was refluxed for 8 hours; and the progress of the reaction was monitor using TLC. After completion of the reaction, the mixture was allowed to cool to room temperature. The orange crystalline solid was separated out which constituted pure compound $\mathbf{L} 1$ with following properties. Yield 94\%, Elemental analysis: Calculated: C, 84.48; H, 5.67; N, 9.85; Found: C, 84.42; H, 5.61; N, 9.78.

Synthesis of L2 (2-(naphthalene-1-yl)-1-(naphthalene-1-ylmethyl)-1H-benzo[d]imidazole): The compound $\mathbf{L} 2$ was synthesized using the same method as L1, naphthaldehyde (3.44 gm, 10 mmoles) was used instead of benzaldehyde and reaction mixture was refluxed for 10 hours. The orange solid was separated out after 10 hours of refluxing which constituted pure compound $\mathbf{L 2}$ with following 
properties. Yield 91\%, Elemental analysis: Calculated: C, 87.47; H, 5.24; N, 7.29; Found: C, 87.41; H, $5.17 ; \mathrm{N}, 9.27$.

Synthesis of L3 (1-((4,5a1-dihydropyren-1-yl)methyl)-2-(pyren-1-yl)-1H-benzo[d]imidazole): The compound $\mathbf{L 3}$ was synthesized using same method as L1, 1-Pyrenecarboxaldehyde (4.96 gm, 10 mmole) was used instead of benzaldehyde and reaction mixture was refluxed for 10 hours. The orange solid was separated out after 10 hours of refluxing which constituted pure compound L3 with following properties. Yield 91\%, Elemental analysis: Calculated: C, 89.86; H, 4.90; N, 5.24; Found: C, 89.82; H, 4.85; N, 5.18. ${ }^{1} \mathrm{H}$ NMR (400 MHz, DMSO-D6) $\delta 8.01-7.94(\mathrm{t}, 4 \mathrm{H}, J=8 H z), 7.86-7.79(\mathrm{t}, 4 \mathrm{H}, J=$ $8 H z), 7.69(\mathrm{t}, 1 \mathrm{H}, J=8 \mathrm{~Hz}), 7.61(\mathrm{t}, 2 \mathrm{H}, J=8 \mathrm{~Hz}), 7.57(\mathrm{t}, 2 \mathrm{H}, J=8 \mathrm{~Hz}), 7.51(\mathrm{t}, 2 \mathrm{H}, J=8 H z), 7.45(\mathrm{t}$, $3 \mathrm{H}, J=8 \mathrm{~Hz}), 7.38(\mathrm{t}, 2 \mathrm{H}, J=8 \mathrm{~Hz}), 7.28(\mathrm{t}, 1 \mathrm{H}, J=8 \mathrm{~Hz}), 7.22(\mathrm{t}, 3 \mathrm{H}, J=8 \mathrm{~Hz}), 6.60(\mathrm{~d}, 1 \mathrm{H}, J=8 \mathrm{~Hz})$, $5.83(\mathrm{~s}, 2 \mathrm{H}) .{ }^{13} \mathrm{C}$ NMR $\left(400 \mathrm{MHz}, \mathrm{DMSO}^{\left.-\mathrm{D}^{6}\right)} \delta 175.70,152.80,151.86,144.40,143.35,135.87,134.94\right.$, $134.13,133.71,133.59,132.46,132.04,131.00,130.69,130.29,129.11,128.92,128.85,128.73,128.39$, $128.27,127.84,127.61,126.99,126.94,126.87,126.59,125.91,125.83,125.53,123.63,123.38,123.19$, $122.79,122.13,120.03,119.60,111.88,111.79,46.12$.

Synthesis of complex R1: Zinc(II)bromide $(100 \mathrm{mmol})$ was dissolved in methanol - tetrahydrofuran $(20 \mathrm{~mL})$ along with ligand L1 $(200 \mathrm{mmol})$. The reaction mixture was heated and stirred for 20 minutes. The color of the solution becomes more intense. The solution was kept undisturbed for 24 hours for slow evaporation. Dark brown needle shaped crystals were formed that were suitable for single crystal data collection. Elemental analysis: Calculated: C, 60.52; H, 4.06; N, 7.06; Found: C, 60.47; H, 4.00; N, 7.01.

Synthesis of complex R2: Zinc(II)chloride $(100 \mathrm{mmol})$ was dissolved in methanol - tetrahydrofuran $(20 \mathrm{~mL})$ along with ligand L1 $(200 \mathrm{mmol})$ The reaction mixture was heated and stirred for 20 minutes. The color of the solution becomes more intense. The solution was kept undisturbed for 24 hours for slow evaporation. Dark brown needle shaped crystals were formed that were suitable for single crystal data collection. Elemental analysis: Calculated: C, 62.70; H, 4.58; N, 7.08; Found: C, 62.67; H, 4.55; N, 7.02.

Synthesis of complex R3: Zinc(II)bromide $(100 \mathrm{mmol})$ was dissolved in methanol - tetrahydrofuran $(20 \mathrm{~mL})$ along with ligand L1 $(200 \mathrm{mmol})$. The reaction mixture was heated and stirred for 20 minutes. The color of the solution becomes more intense. The solution was kept undisturbed for 24 hours for slow 
evaporation. Dark brown needle shaped crystals were formed that were suitable for single crystal data collection. Elemental analysis: Calculated: C, 62.01; H, 3.99; N, 5.04; Found: C, 61.95; H, 3.95; N, 5.00.

\section{ASSOCIATED CONTENT}

\section{Supporting Information}

The Supporting Information is available free of charge on the ACS Publications website at DOI. Absorption and emission properties, ${ }^{1} \mathrm{H}-\mathrm{NMR},{ }^{13} \mathrm{C}-\mathrm{NMR}$, Bond angles and bond length of complex, DLS, Fluorescence microscopy images.

\section{AUTHOR INFORMATION}

\section{Corresponding Author}

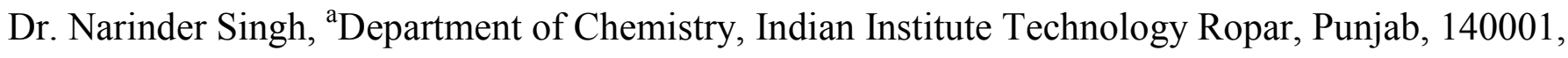
India E-mail: nsingh@iitrpr.ac.in; Tel: +91-1881242176

\section{Acknowledgement}

This work was supported by research grant from Indo-Canada project sponsored by DBT-New Delhi and IC-IMPACTS Canada. A. S. and P. R. are thankful to CSIR-New Delhi (9/1005(0010)/2014-EMR1) and UGC-New Delhi respectively for their fellowship.

\section{Reference}

(1) Gale, P. A.; Caltagirone, C. Anion Sensing by Small Molecules and Molecular Ensembles. Chem. Soc. Rev. 2015, 44 (13), 4212-4227 DOI: 10.1039/C4CS00179F.

(2) Gong, Z.-L.; Zhong, Y.-W. $\mathrm{H}_{2} \mathrm{PO}_{4}{ }^{-}$- and Solvent-Induced Polymorphism of an AmideFunctionalized $\left[\mathrm{Pt}\left(\mathrm{N}^{\wedge} \mathrm{C}^{\wedge} \mathrm{N}\right) \mathrm{Cl}\right]$ Complex. Inorg. Chem. 2016, 55 (20), 10143-10151 DOI: 10.1021/acs.inorgchem.6b01059.

(3) Patra, C.; Bhanja, A. K.; Mahapatra, A.; Mishra, S.; Saha, K. Das; Sinha, C. Coumarinyl Thioether Schiff Base as a Turn-on Fluorescent Zn(II) Sensor and the Complex as Chemosensor for the Selective Recognition of ATP, along with Its Application in Whole Cell Imaging. RSC $A d v$. 2016, 6 (80), 76505-76513 DOI: 10.1039/C6RA12369D. 
(4) Raj, P.; Singh, A.; Kaur, K.; Aree, T.; Singh, A.; Singh, N. Fluorescent Chemosensors for Selective and Sensitive Detection of Phosmet/Chlorpyrifos with Octahedral $\mathrm{Ni}^{2+}$ Complexes. Inorg. Chem. 2016, 55, 4874-4883 DOI: 10.1021/acs.inorgchem.6b00332.

(5) Singh, A.; Singh, A.; Singh, N.; Jang, D. O. A 2-Mercaptobenzimidazole-Based Emissive Cu(I) Complex for Selective Determination of Iodide with Large Stokes Shift. Sensors Actuators B Chem. 2017, 243, 372-379 DOI: 10.1016/j.snb.2016.11.157.

(6) Lu, Q.-S.; Dong, L.; Zhang, J.; Li, J.; Jiang, L.; Huang, Y.; Qin, S.; Hu, C.-W.; Yu, X.-Q. Imidazolium-Functionalized BINOL as a Multifunctional Receptor for Chromogenic and Chiral Anion Recognition. Org. Lett. 2009, 11 (3), 669-672 DOI: 10.1021/o18027303.

(7) Fu, Y.; Mu, L.; Zeng, X.; Zhao, J.-L.; Redshaw, C.; Ni, X.-L.; Yamato, T. An NBD-Armed thiacalix[4]arene-Derived Colorimetric and Fluorometric Chemosensor for $\mathrm{Ag}^{+}: \mathrm{A} \mathrm{Metal-Ligand}$ Receptor of Anions. Dalton Trans. 2013, 42 (10), 3552-3560 DOI: 10.1039/c2dt32115g.

(8) Kundu, T.; Chowdhury, A. D.; De, D.; Mobin, S. M.; Puranik, V. G.; Datta, A.; Lahiri, G. K. Selective Recognition of Fluoride and Acetate by a Newly Designed Ruthenium Framework: Experimental and Theoretical Investigations. Dalt. Trans. 2012, 41 (15), 4484 DOI: $10.1039 / \mathrm{c} 2 \mathrm{dt} 12126 \mathrm{c}$.

(9) Singh, A.; Raj, P.; Singh, N. Benzimidazolium-Based Self-Assembled Fluorescent Aggregates for Sensing and Catalytic Degradation of Diethylchlorophosphate. ACS Appl. Mater. Interfaces 2016, 8, 28641-28651 DOI: 10.1021/acsami.6b09983.

(10) Yang, Y.; Chen, S.; Ni, X. Fluorescent Chemosensor for Nitrate in Acidic Aqueous Solution and. Anal. Chem. 2015, 87 (14), 7461-7466 DOI: 10.1021/acs.analchem.5b01774.

(11) Zhao, J.; Yang, D.; Zhao, Y.; Cao, L.; Zhang, Z.; Yang, X.-J.; Wu, B. Phosphate-Induced Fluorescence of a Tetraphenylethene-Substituted Tripodal Tris(urea) Receptor. Dalt. Trans. 2016, 45 (17), 7360-7365 DOI: 10.1039/C6DT00672H.

(12) Jia, C.; Zuo, W.; Zhang, D.; Yang, X.; Wu, B. Anion Recognition by Oligo-(Thio)urea-Based Receptors. Chem. Commun. 2016, 52, 9614-9627 DOI: 10.1039/C6CC03761E. 
(13) Singh, J.; Singh, A.; Singh, N. Urea Based Organic Nanoparticles for Selective Determination of NADH. RSC Adv. 2014, 4 (106), 61841-61846 DOI: 10.1039/C4RA10209F.

(14) Singh, A.; Singh, A.; Singh, N.; Jang, D. O. A Benzimidazolium-Based Organic Trication: A Selective Fluorescent Sensor for Detecting Cysteine in Water. RSC Adv. 2015, 5 (88), 7208472089 DOI: 10.1039/C5RA14501E.

(15) Wang, S.; Chang, Y.-T. Combinatorial Synthesis of Benzimidazolium Dyes and Its Diversity Directed Application toward GTP-Selective Fluorescent Chemosensors. J. Am. Chem. Soc. 2006, 128 (32), 10380-10381 DOI: 10.1021/ja063733d.

(16) Hargrove, A. E.; Nieto, S.; Zhang, T.; Sessler, J. L.; Anslyn, E. V. Artificial Receptors for the Recognition of Phosphorylated Molecules. Chem. Rev. 2011, 111, 6603-6782 DOI: $10.1021 / \mathrm{cr} 100242 \mathrm{~s}$.

(17) Rommel, S. A.; Sorsche, D.; Rau, S. A Supramolecular H-Bond Driven Light Switch Sensor for Small Anions. Dalt. Trans. 2016, 45 (1), 74-77 DOI: 10.1039/C5DT04152J.

(18) Singh, A.; Singh, A.; Singh, N.; Ok, D. Selective Detection of Hg ( II ) with Benzothiazole-Based F1 Uorescent Organic Cation and the Resultant Complex as a Ratiometric Sensor for Bromide in Water. Tetrahedron 2016, 72 (24), 3535-3541 DOI: 10.1016/j.tet.2016.04.082.

(19) Kumar, S.; Singh, P.; Mahajan, A.; Kumar, S. Aggregation Induced Emission Enhancement in Ionic Self-Assembled Aggregates of Benzimidazolium Based Cyclophane and Sodium Dodecylbenzenesulfonate. Org. Lett. 2013, 15 (13), 3400-3403 DOI: 10.1021/ol401452t.

(20) Yao, J.; Fu, Y.; Xu, W.; Fan, T.; Gao, Y.; He, Q.; Zhu, D.; Cao, H.; Cheng, J. Concise and Efficient Fluorescent Probe via an Intromolecular Charge Transfer for the Chemical Warfare Agent Mimic Diethylchlorophosphate Vapor Detection. Anal. Chem. 2016, 88 (4), 2497-2501 DOI: 10.1021/acs.analchem.5b04777.

(21) Liu, X.; Xu, J.; Lv, Y.; Wu, W.; Liu, W.; Tang, Y. An ATP-Selective, Lanthanide Complex Luminescent Probe. Dalton Trans. 2013, 42 (27), 9840-9846 DOI: 10.1039/c3dt50986a.

(22) Kumar, A.; Pandey, R.; Kumar, A.; Gupta, R. K.; Dubey, M.; Mohammed, A.; Mobin, S. M.; 
Pandey, D. S. Self-Assembled copper(II) Metallacycles Derived from Asymmetric Schiff Base Ligands: Efficient Hosts for ADP/ATP in Phosphate Buffer. Dalt. Trans. 2015, 44, 17152-17165 DOI: $10.1039 / \mathrm{c} 5 \mathrm{dt} 01433 \mathrm{f}$.

(23) Minami, T.; Emami, F.; Nishiyabu, R.; Kubo, Y.; Anzenbacher, P. Quantitative Analysis of Modeled ATP Hydrolysis in Water by a Colorimetric Sensor Array. Chem. Commun. 2016, 52 (10), 2-5 DOI: 10.1039/C6CC02923J.

(24) Vancraenenbroeck, R.; Webb, M. R. A Fluorescent, Reagentless Biosensor for ATP, Based on Malonyl-Coenzyme A Synthetase. ACS Chem. Biol. 2015, 10 (11), 2650-2657 DOI: 10.1021/acschembio.5b00346.

(25) Liu, Z.; Chen, S.; Liu, B.; Wu, J.; Zhou, Y.; He, L. Intracellular Detection of ATP Using an Aptamer Beacon Covalently Linked to Graphene Oxide Resisting Non- Specific Probe Displacement. Anal. Chem. 2014, 86 (519), 1-10.

(26) Asha, K. S.; Bhattacharyya, K.; Mandal, S. Discriminative Detection of Nitro Aromatic Explosives by a Luminescent Metal-organic Framework. J. Mater. Chem. C 2014, 2 (47), 1007310081 DOI: 10.1039/C4TC01982B.

(27) Au, V. K. M.; Zhu, N.; Yam, V. W. W. Luminescent Metallogels of Bis-Cyclometalated alkynylgold(III) Complexes. Inorg. Chem. 2013, 52 (2), 558-567 DOI: 10.1021/ic3007519.

(28) Ghosh, S.; Mishra, M. K.; Ganguly, S.; Desiraju, G. R. Dual Stress and Thermally Driven Mechanical Properties of the Same Organic Crystal: 2,6-Dichlorobenzylidene-4-Fluoro-3Nitroaniline. J. Am. Chem. Soc. 2015, 137 (31), 9912-9921 DOI: 10.1021/jacs.5b05324.

(29) Banik, M.; Gopi, S. P.; Ganguly, S.; Desiraju, G. R. Cocrystal and Salt Forms of Furosemide: Solubility and Diffusion Variations. Cryst. Growth Des. 2016, 16, 5418-5428 DOI: 10.1021/acs.cgd.6b00902.

(30) Rana, L. K.; Sharma, S.; Hundal, G. First Report on Crystal Engineering of Hg(II) Halides with Fully Substituted 3,4-Pyridinedicarboxamides: Generation of Two-Dimensional Coordination Polymers and Linear Zig-Zag Chains of Mercury Metal Ions. Cryst. Growth Des. 2016, 16 (1), 
92-107 DOI: 10.1021/acs.cgd.5b00989.

(31) Jassal, A. K.; Sharma, S.; Hundal, G.; Hundal, M. S. Structural Diversity, Thermal Studies, and Luminescent Properties of Metal Complexes of Dinitrobenzoates: A Single Crystal to Single Crystal Transformation from Dimeric to Polymeric Complex of copper(II). Cryst. Growth Des. 2015, 15 (1), 79-93 DOI: $10.1021 / \mathrm{cg} 500883 \mathrm{w}$.

(32) Chung, C. Y. S.; Li, S. P. Y.; Lo, K. K. W.; Yam, V. W. W. Synthesis and Electrochemical, Photophysical, and Self-Assembly Studies on Water-Soluble pH-Responsive Alkynylplatinum(II) Terpyridine Complexes. Inorg. Chem. 2016, 55 (9), 4650-4663 DOI: 10.1021/acs.inorgchem.6b00513.

(33) Ghosh, S.; Mukherjee, P. S. Self-Assembly of a Nanoscopic Prism via an Organometallic Pt 3 Acceptor and Its Fluorescenct Deetection of Nitroaromatics. 2008, 3 (5), 9-11.

(34) Ghosh, S.; Mukherjee, P. S. Self-Assembly of Molecular Nanoball: Design, Synthesis, and Characterization. J. Org. Chem. 2006, 71 (22), 8412-8416 DOI: 10.1021/jo061311g.

(35) Lee, J. H. Y. H. Y.; Kang, S.; Lee, J. H. Y. H. Y.; Jung, J. H. A Tetrazole-Based Metallogel Induced with $\mathrm{Ag}^{+}$Ion and Its Silver Nanoparticle in Catalysis. Soft Matter 2012, 8, 6557-6563 DOI: $10.1039 / \mathrm{c} 2 \mathrm{sm} 25316 \mathrm{j}$.

(36) Aiyappa, H. B.; Saha, S.; Wadge, P.; Banerjee, R.; Kurungot, S. Fe( III ) Phytate Metallogel as a Prototype Anhydrous, Intermediate Temperature Proton Conductor. Chem. Sci. 2015, 6 (1), 603607 DOI: 10.1039/C4SC02294G.

(37) Tam, A. Y.-Y.; Yam, V. W.-W. Recent Advances in Metallogels. Chem. Soc. Rev. 2013, 42 (4), 1540-1567 DOI: $10.1039 / \mathrm{c} 2 \mathrm{cs} 35354 \mathrm{~g}$.

(38) Feldner, T.; Hring, M.; Saha, S.; Esquena, J.; Banerjee, R.; Daz, D. D. Supramolecular Metallogel That Imparts Self-Healing Properties to Other Gel Networks. Chem. Mater. 2016, 28 (9), 3210 3217 DOI: 10.1021/acs.chemmater.6b01144.

(39) Sarmah, K.; Pandit, G.; Das, A. B.; Sarma, B.; Pratihar, S. Steric Environment Triggered SelfHealing CuII/HgII Bimetallic Gel with Old CuII-Schiff Base Complex as a New Metalloligand. 
Cryst. Growth Des. 2017, 17, 368-380 DOI: 10.1021/ACS.CGD.6B01545.

(40) Maity, D.; Kumar, V.; Govindaraju, T. Reactive Probes for Ratiometric Detection of $\mathrm{Co}^{2+}$ and $\mathrm{Cu}^{+}$Based on ESIPT Mechanism. Org. Lett. 2012, 14, 6008-6011.

(41) Nishizawa, S.; Kato, Y.; Teramae, N. Fluorescence Sensing of Anions via Intramolecular Excimer Formation in a Pyrophosphate-Induced Self-Assembly of a Pyrene-Functionalized Guanidinium Receptor [9]. J. Am. Chem. Soc. 1999, 121 (40), 9463-9464 DOI: 10.1021/ja991497j.

(42) Chen, S.; Shi, Z.; Qin, L.; Jia, H.; Zheng, H. Two New Luminescent Cd(II)-Metal-Organic Frameworks as Bifunctional Chemosensors for Detection of Cations $\mathrm{Fe}^{3+}, \mathrm{Anions}^{\mathrm{CrO}_{4}}{ }^{2-}$, and $\mathrm{Cr}_{2} \mathrm{O}_{7}{ }^{2-}$ in Aqueous Solution. Cryst. Growth Des. 2017, 17, 67-72 DOI: 10.1021/acs.cgd.6b01197.

(43) Wang, D.; Li, S.-M.; Zheng, J.-Q.; Kong, D.-Y.; Zheng, X.-J.; Fang, D.-C.; Jin, L.-P. Coordination-Directed Stacking and Aggregation-Induced Emission Enhancement of the $\mathrm{Zn}$ (II) Schiff Base Complex. Inorg. Chem. 2017, 56, 984-990 DOI: 10.1021/acs.inorgchem.6b02784.

(44) Wang, D.; Li, S.-M.; Li, Y.-F.; Zheng, X.-J.; Jin, L.-P. Hydrogen Bond-Assisted AggregationInduced Emission and Application in the Detection of the Zn(II ) Ion. Dalt. Trans. 2016, 1 (c), 2 5 DOI: 10.1039/C6DT00265J.

(45) Haldar, R.; Prasad, K.; Samanta, P. K.; Pati, S.; Maji, T. K. Luminescent Metal-Organic Complexes of Pyrene or Anthracene Chromophores: Energy Transfer Assisted Amplified Exciplex Emission and $\mathrm{Al}^{3+}$ Sensing. Cryst. Growth Des. 2016, 16 (1), 82-91 DOI: 10.1021/acs.cgd.5b01448.

(46) Manalo, M. N.; Perez, L. M.; LiWang, A. Hydrogen-Bond \& $\pi-\pi$ Base-Stacking Interactions Are Coupled in DNA, As Suggested by Calcd \& Exptl Trans-H Bond 2H Isotope Shifts. J. Am. Chem. Soc. 2007, 129 (37), 11298-11299.

(47) Copeland, K. L.; Pellock, S. J.; Cox, J. R.; Cafiero, M. L.; Tschumper, G. S. Examination of Tyrosine/adenine Stacking Interactions in Protein Complexes. J. Phys. Chem. B 2013, 117 (45), 
14001-14008 DOI: $10.1021 / j p 408027$ j.

(48) Kumar Verma, R.; Takei, F.; Nakatani, K. Synthesis and Photophysical Properties of Fluorescence Molecular Probe for Turn-ON-Type Detection of Cytosine Bulge DNA. Org. Lett. 2016, 18 (13), 3170-3173 DOI: 10.1021/acs.orglett.6b01378.

(49) Xu, Z.; Singh, N. J.; Lim, J.; Pan, J.; Ha, N. K.; Park, S.; Kim, K. S.; Yoon, J. Unique Sandwich Stacking of Pyrene-Adenine-Pyrene for Selective and Ratiometric Fluorescent Sensing of ATP at Physiological pH. J. Am. Chem. Soc. 2009, 131, 15528-15533 DOI: 10.1021/ja906855a.

(50) Kataev, E.; Arnold, R.; Ru, T.; Lang, H. Fluorescence Detection of Adenosine Triphosphate in an Aqueous Solution Using a Combination of Copper(II) Complexes. Inorg. Chem. 2012, 51 (Ii), $7948-7950$.

(51) Sharma, H.; Kaur, N.; Singh, N.; Jang, D. O. Synergetic Catalytic Effect of Ionic Liquids and $\mathrm{ZnO}$ Nanoparticles on the Selective Synthesis of 1,2-Disubstituted Benzimidazoles Using a BallMilling Technique. Green Chem. 2015, 17 (8), 4263-4270 DOI: 10.1039/C5GC00536A.

(52) Bourhis, L. J.; Dolomanov, O. V.; Gildea, R. J.; Howard, J. A. K.; Puschmann, H. The Anatomy of a Comprehensive Constrained, Restrained Refinement Program for the Modern Computing Environment - Olex2 Dissected. Acta Crystallogr. Sect. A Found. Crystallogr. 2015, 71 (1), 5975 DOI: $10.1107 / \mathrm{S} 2053273314022207$.

(53) Morita, Y.; Suzuki, S.; Sato, K.; Takui, T. Synthetic Organic Spin Chemistry for Structurally Well-Defined Open-Shell Graphene Fragments. Nat Chem 2011, 3 (3), 197-204.

(54) Chi, Y.-H.; Yu, L.; Shi, J.-M.; Zhang, Y.-Q.; Hu, T.-Q.; Zhang, G.-Q.; Shi, W.; Cheng, P. $\pi-\pi$ Stacking and Ferromagnetic Coupling Mechanism on a Binuclear $\mathrm{Cu}(\mathrm{II})$ Complex. Dalt. Trans. 2011, 40, 1453-1462 DOI: 10.1039/c0dt01127d.

(55) Mobin, S. M.; Srivastava, A. K.; Mathur, P.; Lahiri, G. K. Vapor-Diffusion-Mediated Single Crystal-to-Single Crystal Transformation of a Discrete Dimeric copper(II) Complex to a Discrete Tetrameric copper(II) Complex. Inorg. Chem. 2009, 48 (11), 4652-4654 DOI: $10.1021 /$ ic $900510 \mathrm{v}$. 
(56) Mobin, S. M.; Srivastava, A. K.; Mathur, P.; Lahiri, G. K. Single-Crystal to Single-Crystal Transformations in Discrete Hydrated Dimeric Copper Complexes. Dalton Trans. 2010, 39 (6), 1447-1449 DOI: 10.1039/b918761h.

(57) Vij, V.; Tiwari, J. N.; Kim, K. S. Covalent versus Charge Transfer Modification of Graphene/Carbon-Nanotubes with Vitamin B1: Co/N/S-C Catalyst toward Excellent Oxygen Reduction. ACS Appl. Mater. Interfaces 2016, 8 (25), 16045-16052 DOI: 10.1021/acsami.6b03546.

(58) Georgakilas, V.; Tiwari, J. N.; Kemp, K. C.; Perman, J. A.; Bourlinos, A. B.; Kim, K. S.; Zboril, R. Noncovalent Functionalization of Graphene and Graphene Oxide for Energy Materials, Biosensing, Catalytic, and Biomedical Applications. Chem. Rev. 2016, 116 (9), 5464-5519 DOI: 10.1021/acs.chemrev.5b00620.

(59) Sivaraman, G.; Anand, T.; Chellappa, D. Development of a Pyrene Based "turn On” Fluorescent Chemosensor for $\mathrm{Hg}^{2+}$. RSC Adv. 2012, 2 (28), 10605 DOI: 10.1039/c2ra21202a.

(60) Vidya, B.; Iniya, M.; Sivaraman, G.; Sumesh, R. V.; chellappa, D. Diverse Benzothiazole Based Chemodosimeters for the Detection of Cyanide in Aqueous Media and in HeLa Cells. Sensors Actuators, B Chem. 2017, 242, 434-442 DOI: 10.1016/j.snb.2016.11.076.

(61) Sivaraman, G.; Anand, T.; Chellappa, D. Pyrene Based Selective-Ratiometric Fluorescent Sensing of Zinc and Pyrophosphate Ions. Anal. Methods 2014, 6 (7), 2343-2348 DOI: 10.1039/C3AY42057D.

(62) Mandal, S.; Kundi, V.; Seth, D. K.; Srikanth, K.; Gupta, P. Studies on Ruthenium Complexes of Pyrene-Appended Schiff Base Ligands. Polyhedron 2014, 80, 290-297 DOI: 10.1016/j.poly.2014.06.005.

(63) Gonell, S.; Peris, E. Pyrene-Based Mono- and Di-N-Heterocyclic Carbene Ligand Complexes of Ruthenium for the Preparation of Mixed Arylated/alkylated Arylpyridines. ACS Catal. 2014, 4 (8), 2811-2817 DOI: 10.1021/cs500735u.

(64) Maity, D.; Bhaumik, C.; Mondal, D.; Baitalik, S. Ru(II) and Os(II) Complexes Based on 
Terpyridyl-Imidazole Ligand Rigidly Linked to Pyrene: Synthesis, Structure, Photophysics, Electrochemistry, and Anion-Sensing Studies. Inorg. Chem. 2013, 52 (24), 13941-13955 DOI: $10.1021 / \mathrm{ic} 401582 \mathrm{~m}$.

(65) Chong, Y. S.; Dial, B. E.; Burns, W. G.; Shimizu, K. D. Covalent Locking and Unlocking of an Atropisomeric Molecular Switch. Chem. Commun. 2012, 48 (9), 1296-1298 DOI: $10.1039 / \mathrm{c} 2 \mathrm{cc} 16511 \mathrm{~b}$.

(66) Dial, B. E.; Pellechia, P. J.; Smith, M. D.; Shimizu, K. D. Proton Grease: An Acid Accelerated Molecular Rotor. J. Am. Chem. Soc. 2012, 134 (8), 3675-3678 DOI: 10.1021/ja2120184.

(67) Liang, L. J.; Zhao, X. J.; Huang, C. Z. Zn(II) Complex of Terpyridine for the Highly Selective Fluorescent Recognition of Pyrophosphate. Analyst 2012, 137 (4), 953-958 DOI: $10.1039 / \mathrm{c} 2 \mathrm{an} 15845 \mathrm{k}$.

(68) Isaia, F.; Aragoni, M. C.; Arca, M.; Bettoschi, A.; Caltagirone, C.; Castellano, C.; Demartin, F.; Lippolis, V.; Pivetta, T.; Valletta, E. Zinc(ii)-Methimazole Complexes: Synthesis and Reactivity. Dalt. Trans. 2015, 44 (21), 9805-9814 DOI: 10.1039/C5DT00917K.

(69) Mesquita, L. M.; André, V.; Esteves, C. V.; Palmeira, T.; Berberan-Santos, M. N.; Mateus, P.; Delgado, R. Dinuclear Zinc(II) Macrocyclic Complex as Receptor for Selective Fluorescence Sensing of Pyrophosphate. Inorg. Chem. 2016, 55 (5), 2212-2219 DOI: 10.1021/acs.inorgchem.5b02596.

(70) Mikata, Y.; Ohnishi, R.; Nishijima, R.; Konno, H. Fluorescent Detection of Phosphate Ion via a Tetranuclear Zinc Complex Supported by a Tetrakisquinoline Ligand and $\mu^{4}-\mathrm{PO}_{4}$ Core. Inorg. Chem. 2016, 55, 11440-11446 DOI: 10.1021/acs.inorgchem.6b01967.

(71) Lovitt, J. I.; Hawes, C. S.; Lynes, A. D.; Haffner, B.; Mobius, M. E.; Gunnlaugsson, T. Coordination Chemistry of N-Picolyl-1,8-Naphthalimides: Colourful Low Molecular Weight Metallo-Gelators and Unique Chelation Behaviours. Inorg. Chem. Front. 2017, 4, 296-308 DOI: 10.1039/C6QI00498A.

(72) Gunnlaugsson, T. Supramolecular Pathways: Accessible Self-Assembly. Nat. Chem. 2016, 8 (1), 
6-7 DOI: $10.1038 /$ nchem.2423.

(73) Jones, C. D.; Steed, J. W. Gels with Sense: Supramolecular Materials That Respond to Heat \{,\} Light and Sound. Chem. Soc. Rev. 2016, 45 (1998) DOI: 10.1039/C6CS00435K.

(74) Fang, W.; Liu, C.; Yu, F.; Liu, Y.; Li, Z.; Chen, L.; Bao, X.; Tu, T. Macroscopic and Fluorescent Discrimination of Adenosine Triphosphate via Selective Metallo-Hydrogel Formation: A Visual, Practical, and Reliable Rehearsal toward Cellular Imaging. ACS Appl. Mater. Interfaces 2016, 8 (32), 20583-20590 DOI: 10.1021/acsami.6b05804.

(75) Jung, S. H.; Kim, K. Y.; Lee, J. H.; Moon, C. J.; Han, N. S.; Park, S.-J.; Kang, D.; Song, J. K.; Lee, S. S.; Choi, M. Y.; Jaworski, J.; Jung, J. H. Self-Assembled Tb ${ }^{3+}$ Complex Probe for Quantitative Analysis of ATP during Its Enzymatic Hydrolysis via Time-Resolved Luminescence in Vitro and in Vivo. ACS Appl. Mater. Interfaces 2017, 9, 722-729 DOI: 10.1021/acsami.6b12857.

(76) Bhattacharya, S.; Sengupta, S.; Bala, S.; Goswami, A.; Ganguly, S.; Mondal, R. Pyrazole-Based Metallogels Showing an Unprecedented Colorimetric Ammonia Gas Sensing through Gel-to-Gel Transformation with a Rare Event of Time-Dependent Morphology Transformation. Cryst. Growth Des. 2014, 14 (5), 2366-2374 DOI: 10.1021/cg5000827.

(77) Ai, Y.; Li, Y.; Ma, H.; Su, C.-Y.; Yam, V. W.-W. Cyclometalated Platinum(II) Complexes of 1,3Bis(1- $N$-Butylpyrazol-3-Yl)benzenes: Synthesis, Characterization, Electrochemical, Photophysical, and Gelation Behavior Studies. Inorg. Chem. 2016, 55 (22), 11920-11929 DOI: 10.1021/acs.inorgchem.6b02033.

(78) Samanta, S.; Dey, P.; Ramesh, A.; Das, G. A Solo Fluorogenic Probe for the Real-Time Sensing of $\mathrm{SO}_{3}{ }^{2-}$ and $\mathrm{SO}_{4}{ }^{2-} / \mathrm{HSO}_{4}{ }^{-}$in Aqueous Medium and Live Cells by Distinct Turn-on Emission Signals. Chem. Commun. 2016, 52 (68), 10381-10384 DOI: 10.1039/C6CC03910C.

(79) Kumar, R.; Sandhu, S.; Singh, P.; Kumar, S. Water Dispersed Fluorescent Organic Aggregates for the Picomolar Detection of $\mathrm{ClO}_{4}{ }^{-}$in Water, Soil and Blood Serum and the Attogram Detection of $\mathrm{ClO}_{4}{ }^{-}$in the Solid State by a Contact Mode Method. J. Mater. Chem. C 2016, 4 (31), 7420-7429 DOI: 10.1039/C6TC01891B. 
(80) (a) Haldar, R.; Rao, K. V.; George, S. J.; Maji, T. K.; Exciplex Formation and Energy Transfer in Self Assembled Metal-Organic Hybrid System. Chem. Eur. J. 2012, 18, 5848 - 5852. DOI:

10.1002 /chem.201103827 (b) Prasad, K.; Haldar, R.; George, S. J.; Maji, T. K. Rational design of a pyrene based luminescent porous Supramolecular framework: excimer emission and energy Transfer. $\boldsymbol{R S C} \boldsymbol{A d v}$., 2015,5, 74986- 74993. 


\section{Graphical Abstract}
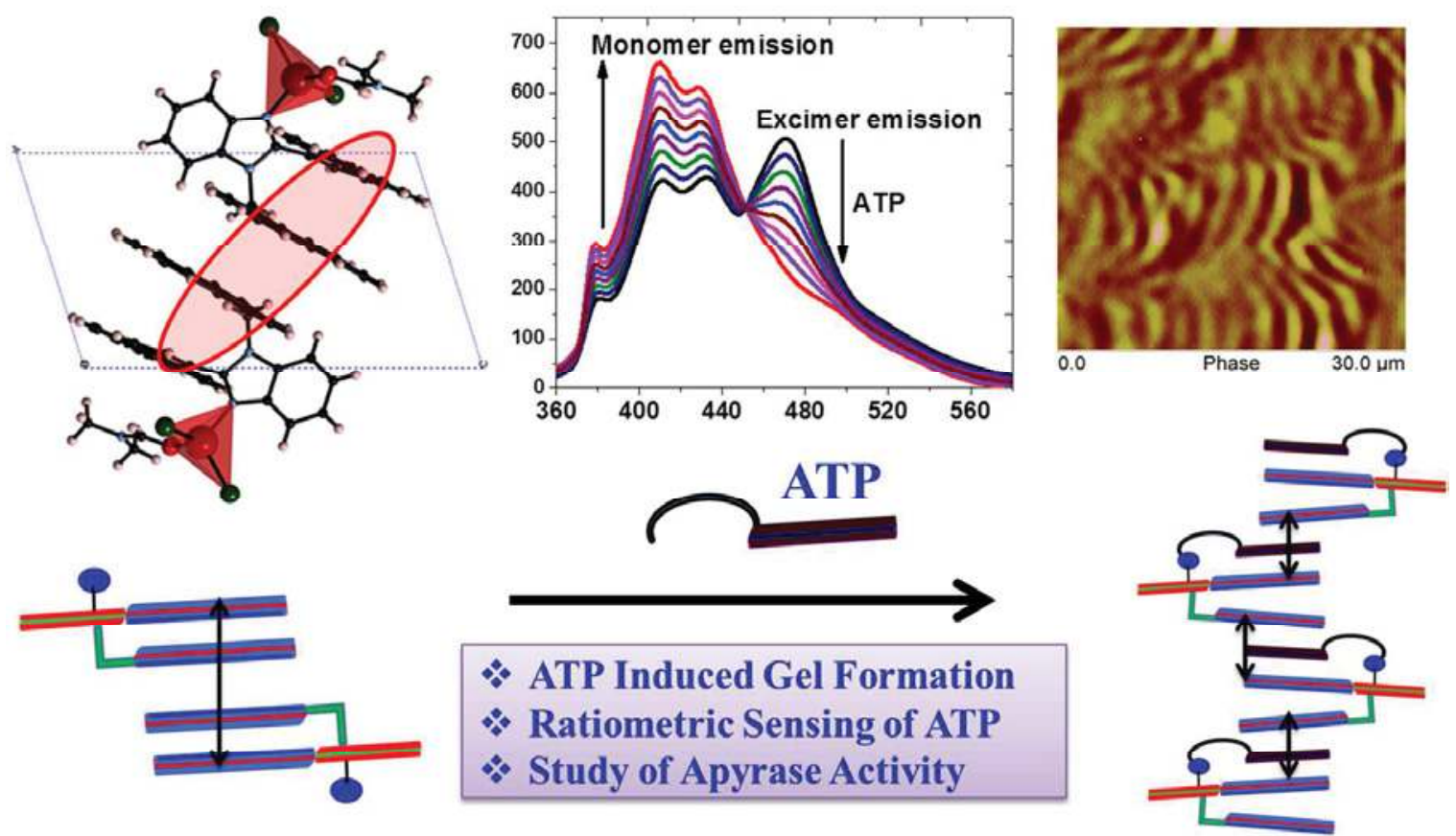

$\pi-\pi$ stacking In pyrene rings

$$
\begin{gathered}
\pi-\pi \text { stacking } \\
\text { pyrene - adenime - pyrene }
\end{gathered}
$$

Synopsis: Ratiometric sensing of ATP was achieved to demonstrate the ATP hydrolysis mechanism using Apyrase enzyme 